\author{
UNIVERSIDADE DE SÃO PAULO \\ FACULDADE DE MEDICINA DE RIBEIRÃO PRETO
}

JULIANA MAIA FARIAS

Protocolo de condutas em uveítes não infecciosas

Ribeirão Preto

2021 


\author{
JULIANA MAIA FARIAS
}

\title{
Protocolo de condutas em uveítes não infecciosas
}

\section{Versão Corrigida}

Dissertação apresentada à Faculdade de Medicina de Ribeirão Preto da Universidade de São Paulo para obtenção do Título de Mestre em Ciências.

Área de Concentração: Oftalmologia

Orientador: Prof. Dr. João Marcello Fórtes Furtado

Ribeirão Preto 
Autorizo a reprodução e divulgação total ou parcial deste trabalho, por qualquer meio convencional ou eletrônico, para fins de estudo e pesquisa, desde que citada a fonte

\section{FICHA CATALOGRÁFICA}

Farias, Juliana Maia

Protocolo de condutas em uveítes não infecciosas. Ribeirão Preto, 2021.

84p.: 15il. ; $30 \mathrm{~cm}$

Dissertação de Mestrado, apresentada à Faculdade de Medicina de Ribeirão Preto/USP. Área de concentração: Oftalmologia.

Orientador: Fortes Furtado, João Marcello.

1. Uveítes não infecciosas. 2. Fluxogramas. 3. Investigação. 4. Tratamento. 


\section{Folha de aprovação}

Aluno: Farias, Juliana Maia

Título: Protocolo de condutas em uveítes não infecciosas

Dissertação apresentada à Faculdade de Medicina de Ribeirão Preto da Universidade de São Paulo, para a obtenção do título de Mestre em Ciência.

Área de Concentração: Oftalmologia

Aprovado em:

Banca Examinadora

Prof. Dr.

Instituição:

Assinatura:

Prof. Dr.

Instituição:

Assinatura:

Prof. Dr.

Instituição:

Assinatura: 


\section{Dedicatória}

Aos meus pais, pelo incondicional apoio no desenvolvimento deste trabalho, compreendendo minhas ausências e incentivando-me a evoluir profissionalmente.

Aos meus irmãos, que sempre estão comigo em todos os momentos, representando uma base sólida em que sempre posso me apoiar.

Aos meus amigos Cibelle, Cyntia, Isabelle e Lucas, pelas conversas, sugestões e apoio nos momentos de dificuldade.

Ao meu esposo Celso, por todo apoio e incentivo, acreditando em mim sempre, especialmente nos momentos de maior dificuldade.

À minha Belinha, pela companhia. 


\section{Agradecimentos}

O presente trabalho foi realizado com apoio da Coordenação de Aperfeiçoamento de Pessoal de Nível Superior - Brasil (CAPES)- Código de Financiamento 001.

Ao professor Dr. João Marcello Fortes Furtado, pela oportunidade de cursar o fellow em Uveítes e o Mestrado Profissional, e por toda a paciência e dedicação ao logo dessa jornada. Mesmo ciente de minhas dificuldades na produção deste trabalho acadêmico, sempre esteve disponível com muita paciência para me oferecer o suporte necessário à sua conclusão. Enfim, só tenho a agradecer por todas as lições que me foram passadas e que certamente contribuíram para minha formação profissional e também pessoal.

Ao Dr. Rafael Estevão de Angelis, pela atenção e principalmente pela disponibilidade para esclarecer as muitas dúvidas que Ihe apresentei, sempre com muita didática e paciência, ao longo desses dois anos.

À Dra. Luciana Martins de Carvalho, ao Dr. Rodrigo Luppino Assad, ao Dr. Rodrigo Oliveira e ao Dr. Tiago Eugenio Faria e Arantes, pelas sugestões e disponibilidade, mesmo nos tempos difíceis de pandemia, através da realização de vídeochamadas e e-mails.

À Nathália Oliveira, Secretária do PPG Mestrado da FMRP-USP, pelo apoio e esclarecimento das dúvidas quanto aos prazos e formalidades para a entrega do trabalho.

A todos os residentes e fellows de oftalmologia, que de forma direta e indireta contribuíram para a realização deste estudo.

Aos funcionários e colaboradores da Faculdade de Medicina, pela receptividade e acolhimento. 


\section{Resumo}

FARIAS, J. M. Protocolo de condutas em uveítes não infecciosas. 2021. Dissertação (Mestrado). Faculdade de Medicina de Ribeirão Preto-USP. Ribeirão Preto-SP. 2021.

Introdução: Em 2018, foi criado no Hospital das Clínicas de Ribeirão Preto o ambulatório conjunto da oftalmologia e da reumatologia para atendimento dos casos de uveítes. Isso trouxe vantagens para os pacientes e para os especialistas, como menor tempo de espera para marcação de consultas, otimização do tratamento e maior aprendizagem do corpo clinico. Por outro lado, observou-se a necessidade de padronizar as condutas para oferecer melhor assistência ao paciente. Objetivo: Elaborar um protocolo de condutas para investigação, tratamento e seguimento dos pacientes com uveítes não infecciosas. Metodologia: Para a criação do protocolo, houve a elaboração de fluxogramas de investigação e de tratamento das doenças. Os primeiros basearam-se no livro de uveítes da Academia Americana de Oftalmologia, no Protocolo Clínico e Diretrizes Terapêuticas das Uveítes não Infecciosas do Ministério da Sáude e na opinião dos especialistas. Já em relação aos fluxogramas de condutas terapêuticas, a sua composição deu-se a partir de duas buscas no Pubmed de artigos publicados no período de janeiro de 1999 a setembro de 2020 , das sugestões dos colaboradores do projeto e da análise dos orientadores dos ambulatórios. Na primeira busca, as palavras-chave foram: "non-infectious uveitis", "non-infectious scleritis", "immunosuppressive therapy and uveitis", "immunomodulatory therapy and uveitis", "guidelines and uveitis", "guidelines and non-infectious uveitis" e "meta-analysis and uveitis". Já na segunda, foram: "idiopathic anterior uveitis" "Vogt-Koyanagi-Harada", "sympathetic opthalmia", "juvenile idiopathic arthritis associated uveitis", "uveitis HLA-B27", "idiopathic scleritis", "pars planitis", "Behçet uveitis", "sarcoidosis uveitis". A escolha dessas doenças da segunda busca foi embasada no estudo de Gonzalez e colaboradores, o qual relata as causas mais comuns de uveíte na cidade de São Paulo. Como não há registro no nosso ambulatório, acreditase que as causas devem ser semelhantes. Resultados: Foram encontrados 3.886 artigos na primeira busca e 9.940 artigos na segunda. Destes foram analisados 100 artigos. Na triagem, utilizou-se o aplicativo Rayyan. Já a criação 
dos fluxogramas ocorreu através do programa CmapTools. Então, foram preparados quatro fluxogramas de investigação com base na classificação do Standardization of Uveitis Nomenclature- SUM, que são: uveíte anterior, posterior, intermediária e panuveíte. O padrão é o mesmo, já que em todos constam os seguintes dados: as doenças mais comuns; as suas principais características; o diagnóstico e o tratamento. Em relação aos fluxogramas de tratamento, foram criados sete deles, correspondendo às doenças já citadas na segunda busca. Ademais, foram elaborados os resumos das doenças e das medicações mais citadas nos artigos e usadas na prática. O resumo das doenças é composto por definição, etiologia, diagnóstico, dignóstico diferencial e tratamento. Já no que diz respeito às drogas, sua estrutura se baseou nos seguintes tópicos: apresentação da medicação, o mecanismo de ação, a dosagem máxima, a posologia, os efeitos colaterais, a dose de manutenção, além da duração dos retornos para as consultas subsequentes. Conclusão: Este protocolo de condutas tem como finalidade auxiliar os oftalmologistas e os reumatologistas na conduta diagnóstica e terapêutica, garantindo uma maior eficiência na tomada de decisões e uma melhor assistência ao paciente.

Palavras-chave: Uveítes não infecciosas. Fluxogramas. Investigação. Tratamento. 


\begin{abstract}
FARIAS, J. M. Protocol of conduct in non-infectious uveitis. 2021. Dissertation (Masters). Ribeirão Preto Medical School University of São Paulo, Ribeirão Preto, 2021.

Introduction: In 2018, a joint ophthalmology and rheumatology outpatient clinic
\end{abstract} for uveitis cases was created at the Hospital das Clínicas in Ribeirão Preto. This brought advantages to patients and specialists, such as shorter waiting times for appointments, optimization of treatment and greater learning for the clinical staff. On the other hand, there was a need to standardize according to the conducts to offer the best care to the patient. Objective: To develop a protocol for conducting investigation, treatment and follow-up of patients with noninfectious patients. Methodology: For the creation of the protocol, there was the elaboration of flowcharts for investigation and treatment of diseases. The first ones were based on the uveitis book of the American Academy of Ophthalmology, the Clinical Protocol and Therapeutic Guidelines for NonInfectious Uveitis of the Ministry of Health and the opinion of experts. Regarding the flowcharts of therapeutic conducts, their composition was based on two searches in Pubmed for articles published from January 1999 to September 2020, the suggestions of the project's collaborators and the analysis of the ambulatory advisors. In the first search, the keywords were: "non-infectious uveitis", "non-infectious scleritis", "immunosuppressive therapy and uveitis", "immunomodulatory therapy and uveitis", "guidelines and uveitis", "guidelines and non-infectious" uveitis "and" meta-analysis and uveitis. "In the second, they were:" idiopathic anterior uveitis", "Vogt-Koyanagi-Harada", "sympathetic opthalmia", "juvenile idiopathic arthritis associated uveitis", "uveitis HLA-B27", "Idiopathic scleritis", "pars planitis", "Behçet uveitis", "sarcoidosis uveitis." The choice of these diseases in the second search was based on the study by Gonzalez et al., Which reports the most common causes of uveitis in the city of São Paulo As there is no record in our clinic, it is believed that the causes must be similar. Results: 3,886 articles were found in the first search and 9,940 articles in the second. Of these, 200 articles were analyzed. In screening, the Rayyan application was used. Flowcharts were created using the CmapTools program. Then, four investigation flowcharts were prepared based on the classification of the Standardization of Uveitis Nomenclature- SUN), which are: anterior, posterior, intermediate uveitis and panuveitis. The pattern is the same, 
since all of them contain the following data: the most common diseases; its main characteristics; diagnosis and treatment. Regarding the treatment flowcharts, seven of them were created, corresponding to the diseases already mentioned in the second search. In addition, summaries of the diseases and medications most cited in the articles were prepared and used in practice. The summary of diseases consists of definition, etiology, diagnosis, differential diagnosis and treatment. With regard to drugs, its structure was based on the following topics: presentation of the medication, the mechanism of action, the maximum dosage, the dosage, side effects, the maintenance dose, in addition to the duration of the returns for subsequent consultations. Conclusion: This conduct protocol aims to assist ophthalmologists and rheumatologists in diagnostic and therapeutic conduct, ensuring greater efficiency in decision making and better patient care.

Keywords: Non-infectious uveitis. Flowcharts. Investigation. Treatment. 


\section{Lista de Abreviaturas e Siglas}

AAO: Academia Americana de Oftalmologia

AINES: Anti-inflamatórios Não Esteroides

Anti-HBc: Hepatitis B Core Antigen Antibody

Anti-HCV: Hepatitis C Virus Antibody

APMPPE: Epiteliopatia Pigmentária Placóide Posterior Multifocal Aguda

CBO: Conselho Brasileiro de Oftalmologia

Cr: Creatinina

DUSN: Neuroretinite Unilateral Subaguda Difusa

DMD: Drogas Modificadoras de Doença

ECA: Enzima Conversora de Angiotensina

ELISA: Enzyme Linked Immuno Sorbent Assay

EULAR: European League Against Rheumatism

EV: Endovenosa

FAN: Fator Anti-Nuclear

FTA- abs: Fluorescent Treponemal Antibody Absorption Test

FR: Fator Reumatóide

HBsAg: Hepatitis B Surface Antigen

HC: Hemograma Completo

HCFMRP: Hospital das Clínicas da Faculdade de Medicina de Ribeirão Preto

HDL: High Density Lipoprotein

HIV: Human Immunodeficiency Virus

HLA-B27: Antígeno Leucocitário Humano B27

IGRA: Interferon Gamma Release Assay

IURE: Ambulatório Integrado de Oftalmologia Uveíte e Reumatologia Pediátrica

IV: Intravenosa

MEWDS: Multiple Evanescent White Dot Syndrome

MTX: Metotrexato

PA + P: incidência póstero-anterior e perfil

PCDT- Protocolos Clínicos e Diretrizes Terapêuticas

PKs: Precipitados Ceráticos

PPD: Purified Protein Derivative 
RAU: Ambulatório de Reumatologia Adulto e Uveíte

RM: Ressonância Magnética

SBU: Sociedade Brasileira de Uveítes

SC: Subcutânea

SUN- Standardization of Uveitis Nomenclature

TC: Tomografia Computadorizada

TGO: Transaminase Glutâmico- Oxalacética

TGP: Transaminase Glutâmico-Pirúvica

TNF: Fator de Necrose Tumoral

TRM: Teste Rápido Molecular

Ur: Ureia

VDRL: Venereal Disease Research Laboratory

VO: Via Oral

VR: Valor de Referência

ß-HCG: Gonadotrofina Coriônica Humana 


\section{Lista de Figuras}

Figura 1- Exemplo de busca no Pubmed com os termos "meta-analysis and uveitis".

Figura 2- Exemplo de como realizar a importação de artigos no aplicativo Rayyan. 23

Figura 3- Exemplo da estrutura do aplicativo Rayyan. 23

Figura 4- Fluxograma de condutas nas causas mais frequentes de uveíte anterior

Figura 5- Fluxograma de condutas nas causas mais frequentes de uveíte posterior. 28

Figura 6- Fluxograma de condutas nas causas mais frequentes de uveíte intermediária.

Figura 7- Fluxograma de condutas nas causas mais frequentes de panuveíte. 30

Figura 8- Fluxograma de condutas para tratamento da Artrite Idiopática Juvenil. 35

Figura 9- Fluxograma de condutas para tratamento de Behçet 36

Figura10- Fluxograma de condutas para tratamento da Sarcoidose 37

Figura 11- Fluxograma de condutas para tratamento da Esclerite Idiopática...38 Figura 12- Fluxograma de condutas para tratamento da Pars Planite .39

Figura 13- Fluxograma de condutas para tratamento da HLA-B27/

Espondiloartropatias. 40

Figura 14: Fluxograma de condutas de tratamento em Uveíte anterior 41

Figura 15: Fluxograma de condutas de tratamento em Vogt-Koyanagi-Harada 


\section{Lista de Tabelas}

Tabela- 1 Termos encontrados na primeira busca no Pubmed.......................31

Tabela- 2 Termos encontrados na segunda busca no Pubmed.......................32 


\section{Sumário}

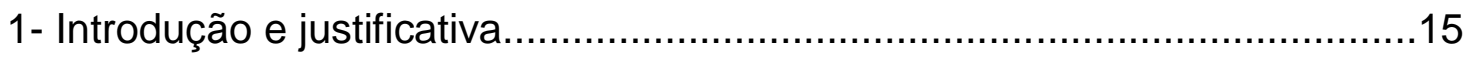

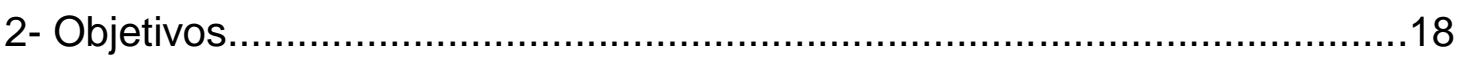

2.1- Objetivo geral.......................................................... 18

2.2- Objetivos específicos....................................................... 18

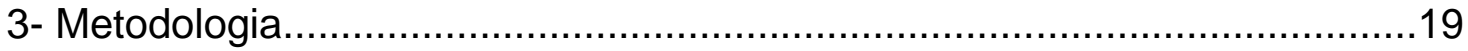

3.1- Criação dos fluxogramas de investigação....................................19

3.2- Criação dos fluxogramas de condutas terapêuticas das principais uveítes não infecciosas.

3.3- Resumo das drogas mais utilizadas em uveítes não infecciosas .25

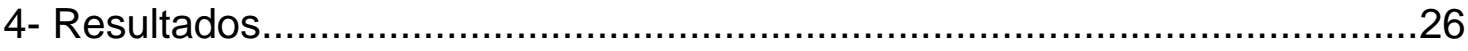

4.1- Criação dos fluxogramas de investigação.................................26

4.2- Criação dos fluxogramas de condutas terapêuticas das principais uveítes não infecciosas .........................................................................

4.2.1- Resumo Artrite Idiopática Juvenil...............................43

4.2.2- Resumo Behçet.....................................................45

4.2.3- Resumo Sarcoidose.............................................47

4.2.4- Resumo Esclerite.....................................................50

4.2.5- Resumo Pars Planite....................................................52

4.2.6- Resumo HLA-B27/Espondiloartroartrites........................54

4.2.7- Resumo Uveíte anterior idiopática.................................56

4.2.8- Resumo Vogt-Koyanagi-Harada.................................58

4.3- Resumo das drogas mais utilizadas em uveítes não infecciosas...60

4.3.1- Resumo Metotrexato 61

4.3.2- Resumo Azatioprina..................................................63

4.3.3- Resumo Adalimumab................................................65

4.3.4- Resumo Geral das medicações..................................66

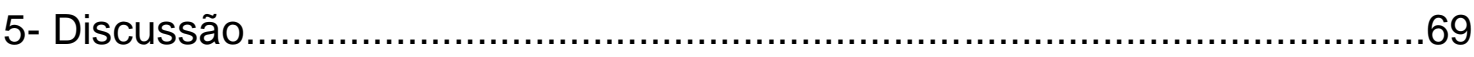

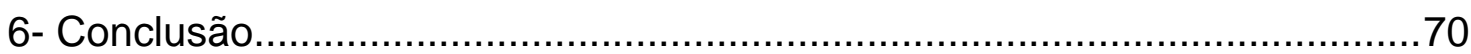

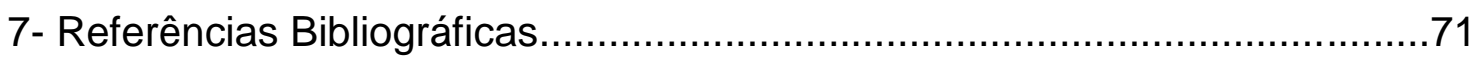




\section{Introdução e justificativa}

Uveíte é um processo inflamatório do olho que acomete o trato uveal, sendo este composto pela íris, corpo ciliar e coroide. Pode também acometer estruturas adjacentes como retina, nervo óptico e vítreo.(1) Nos países ocidentais, ela é responsável por $15 \%$ das causas de cegueira. (2)(3)

Estudos mostram que 60 a $80 \%$ das uveítes acometem a população economicamente ativa, gerando, assim, um prejuízo econômico para a sociedade, pois ocorrerão faltas ao trabalho, perda ou diminuição da produtividade, além de afastamentos permanentes devido à incapacidade visual. (4)

As uveítes podem ser classificadas de forma anatômica em quatro tipos: anterior, intermediária, posterior e panuveíte. A uveíte anterior caracteriza-se quando o sítio primário da inflamação acomete a íris ou parte anterior do corpo ciliar. A uveíte intermediária é aquela cujo vítreo é o principal local de inflamação. Já a uveíte posterior acomete primariamente a retina e a coroide. Por fim, a panuveíte revela-se quando não se consegue definir o sítio primário da inflamação, e esta acomete a câmara anterior, o vítreo, a retina e a coróide. (5)

A uveíte pode ter diversas etiologias, sendo elas classificadas em infecciosas, não infecciosas, neoplásicas, pós-trauma e idiopáticas. As uveítes causadas por doenças infecciosas têm uma maior prevalência em países em desenvolvimento, sendo responsável por 30 a $50 \%$ dos casos. Já as causas não infecciosas têm uma maior prevalência em países desenvolvidos. (6)

$\mathrm{Na}$ grande maioria dos casos das uveítes não infecciosas, há a necessidade do uso de corticoides para controle da inflamação ocular e diminuição de riscos de sequelas visuais. Nos casos de terapia tópica, sabe-se que o uso prolongado de corticoide pode levar a complicações, como catarata e glaucoma. Já nos casos da terapia sistêmica, tal situação pode contribuir para osteoporose, distúrbios eletrolíticos e alterações endócrinas e dermatológicas. (7) Dessa forma, faz-se necessário o uso de uma terapia poupadora de corticoide, que pode ser feita com imunossupressores para 
controle dos sintomas oftalmológicos. Na grande maioria das vezes, quem faz o manejo dessas medicações são os reumatologistas.

Sabe-se que a uveíte é a principal manifestação oftalmológica das doenças reumatológicas. (1) Frise-se que a interação entre o oftalmologista e o reumatologista é essencial, pois muitas vezes os quadros oculares necessitam de parecer do reumatologista para o diagnóstico das doenças sistêmicas reumatológicas. E, por outro lado, o reumatologista necessita da assistência do oftalmologista para verificar se o paciente apresenta sinais oculares de atividade de doença.

Dessa maneira, em 2018, foram criados no Hospital das Clínicas de Ribeirão Preto o Ambulatório de Reumatologia Adulto e Uveíte (RAU), que ocorre às quintas-feiras, no período da tarde, e também o Ambulatório Integrado de Oftalmologia Uveíte e Reumatologia Pediátrica (IURE), que ocorre às segundas-feiras, igualmente no período da tarde.

Quanto aos critérios de elegibilidade de ingresso e seguimento dos pacientes nestes ambulatórios, observam-se os seguintes: aqueles com inflamação ocular de etiologia não infecciosa, necessitando de avaliação clínica para investigação de doença reumatológica, e os que precisam de imunossupressão, não tendo doença reumatológica diagnosticada. Além desses, tem-se os que apresentam uma doença reumatológica de base e que, em algum momento durante o curso clínico da doença, pode ocorrer um quadro de uveíte.

Antes da criação deste ambulatório, o paciente era visto por uma das especialidades, oftalmologia ou reumatologia, e, em seguida, encaminhado para o ambulatório da segunda especialidade, ocasionando múltiplas visitas ao serviço, demora para a conduta terapêutica e potencialmente trazendo maiores complicações da doença.

Com o ambulatório de atendimento conjunto, ocorre o encaminhamento para as duas especialidades, de modo que durante a consulta com 0 reumatologista avalia-se a parte clínica do paciente. Em seguida, o oftalmologista realiza o exame ocular. Finalmente, as duas equipes determinam a melhor conduta caso a caso. 
Esta interação oferece muitas vantagens, como uma melhora na assistência ao paciente, bem como na aprendizagem do corpo clínico, que é composto por especialistas e médicos residentes da oftalmologia, da clínica médica, da reumatologia e da reumatopediatria. Ademais, a avaliação conjunta do caso e a padronização de condutas a serem adotadas diminuiria o número de visitas ao hospital e reduziria os custos do serviço.

Além disso, o tempo de espera para a marcação de consulta com a reumatologia e com a oftalmologia seria abreviado, gerando uma otimização do tratamento, pois, consequentemente, o paciente teria um acesso mais fácil e precoce às medicações imunossupressoras, reduzindo os efeitos colaterais das medicações, assim como as complicações da doença.

Face ao exposto, percebe-se a necessidade de uma padronização de condutas. Dessa forma, o objetivo do trabalho consiste em elaborar um protocolo para investigação, tratamento e seguimento do paciente com uveítes de origem não infecciosa. 


\section{Objetivos}

\subsection{Objetivo geral}

Elaborar protocolo de condutas diagnósticas e terapêuticas em uveítes não infecciosas.

\subsection{Objetivos específicos}

1. Criar fluxogramas de investigação, baseados nas principais causas de uveíte, divididas de acordo com a classificação anatômica das mesmas.

2. Produzir fluxogramas de condutas terapêuticas das principais uveítes não infecciosas do nosso meio.

3. Elaborar resumo das drogas mais comumente usadas no tratamento das uveítes não infecciosas. 


\section{Metodologia}

\subsection{Criação dos fluxogramas de investigação}

Inicialmente, foi realizada uma busca por protocolos em uveítes não infecciosas já publicados no sítio da Academia Americana de Oftalmologia (AAO) (https://www.aao.org/guidelines-browse?subspecialty=uveitis) (8), no $\begin{array}{llll}\text { Conselho } & \text { Brasileiro } & \text { Oftalmologia } & \text { (CBO) }\end{array}$ (https://www.cbo.net.br/novo/classe-medica/)(9), na Sociedade Brasileira de Uveítes (SBU) (http://www.uveitesbrasil.com.br/paginas/view/artigos.html)(10) e no sítio do Ministério da Saúde (http://saude.gov.br/protocolos-e-diretrizes)(11).

Para a preparação dos fluxogramas, utilizou-se um programa que ajuda a produzir mapas conceituais cujo nome é Cmaptools(12), o qual pode ser obtido em sua versão 6.02 através de download (https://cmaptools.br.uptodown.com/windows)(12).

A partir disso, foram desenvolvidos fluxogramas por classificação anatômica nas seguintes categorias: uveíte anterior, posterior, intermediária e panuveíte, as quais são baseadas na padronização da nomenclatura das uveítes (Standardization of Uveitis Nomenclature- SUM) (5). É importante dizer que nesses fluxogramas incluiu-se tanto doenças infecciosas como não infecciosas, pois a conclusão de que a uveíte é de causa não infecciosa depende da exclusão das primeiras.

Vale esclarecer que a elaboração dos fluxogramas direcionados ao diagnóstico diferencial das uveítes com base em sua classificação anatômica(5) deu-se a partir da prática diária no ambulatório da oftalmologia e do RAU, bem como na pesquisa de condutas no livro de uveítes da $A A O(13)$ e na busca por protocolos já publicados.

Em relação às doenças escolhidas para compor os fluxogramas de investigação, utilizamos como base o estudo publicado por Gonzalez e colaboradores, no qual constam as uveítes não infecciosas mais comumente encontradas no ambulatório de um serviço terciário do Hospital São Paulo, na cidade de São Paulo. Como não há o registro de dados em nosso serviço, acredita-se que na nossa população as principais causas de uveítes devam ser semelhantes a desse estudo. (14) 
Quanto a sua estrutura, o padrão foi o mesmo, já que em todos constam os seguintes dados: as doenças mais comuns; as suas principais características; o diagnóstico e o tratamento.

Após a realização dos fluxogramas por classificação anatômica, houve a sua análise pela equipe da oftalmologia e da reumatologia que atua no RAU. Depois, algumas sugestões e modificações foram propostas a partir das suas experiências e das condutas adotadas diariamente. 


\subsection{Criação dos fluxogramas de condutas terapêuticas das principais uveítes não infecciosas}

Foram realizadas duas revisões bibliográficas na base de dados da Biblioteca Nacional de Medicina e do Instituto Nacional de Saúde dos Estados Unidos Pubmed (https://www.ncbi.nlm.nih.gov/pubmed/)(15). O primeiro processo de busca baseou-se nas palavras-chaves: "non-infectious uveitis", "non-infectious scleritis", "immunosuppressive therapy and uveitis", "immunomodulatory therapy and uveitis", "guidelines and uveitis", "guidelines and non-infectious uveitis" e "meta-analysis and uveitis".

Já o segundo processo de busca no Pubmed apoiou-se, novamente, no estudo publicado por Gonzalez e colaboradores(14). Neste estudo, procurou-se identificar as causas mais comuns de uveítes bem como os respectivos percentuais de incidência em relação às causas autoimunes, nos termos a seguir. A uveíte idiopática anterior e Vogt-Koyanagi-Harada representaram, respectivamente, $18,40 \%$ e $13,98 \%$ das causas não infecciosas encontradas. A artrite idiopática juvenil e as uveítes por HLA-B27, por sua vez, tiveram um percentual de $11,85 \%$. Já a esclerite idiopática apresentou $9,20 \%$ das causas. Quanto a pars planite e a doença de Behçet, foram encontrados, respectivamente, os seguintes percentuais: $8,84 \%$ e 6,54\%. Por fim, a sarcoidose e a oftalmia simpática representaram, nesta ordem, os percentuais de $4,24 \%$ e $1,06 \%$. Assim, observou-se acima que as palavras-chaves para a segunda busca foram: "idiopathic anterior uveitis", "Vogt-Koyanagi-Harada", "sympathetic opthalmia", "juvenile idiopathic arthritis associated uveitis", "uveitis HLA-B27"," idiopathic scleritis", "pars planitis", "Behçet uveitis", "sarcoidosis uveitis".

O processo de revisão foi efetuado por meio do Rayyan QCRI (https://rayyan.qcri.org/welcome)(16) um aplicativo gratuito encontrado na internet que ajuda na triagem dos artigos selecionados na base de dados. Para usar o aplicativo, basta criar uma conta vinculada ao endereço eletrônico.

Então, colocando-se no Pubmed a palavra-chave, por exemplo, "metaanalysis and uveitis", encontram-se uma série de artigos. Em seguida, deve-se clicar na palavra "send to" e no item "file" escolhendo o formato XML. A escolha deste formato ocorre porque no próprio aplicativo Rayyan há orientações para 
a sua utilização nas buscas do Pubmed. Após este processo, os artigos são enviados para a pasta downloads. (Figura1)

Figura 1- Exemplo de busca no Pubmed com os termos "meta-analysis and uveitis".

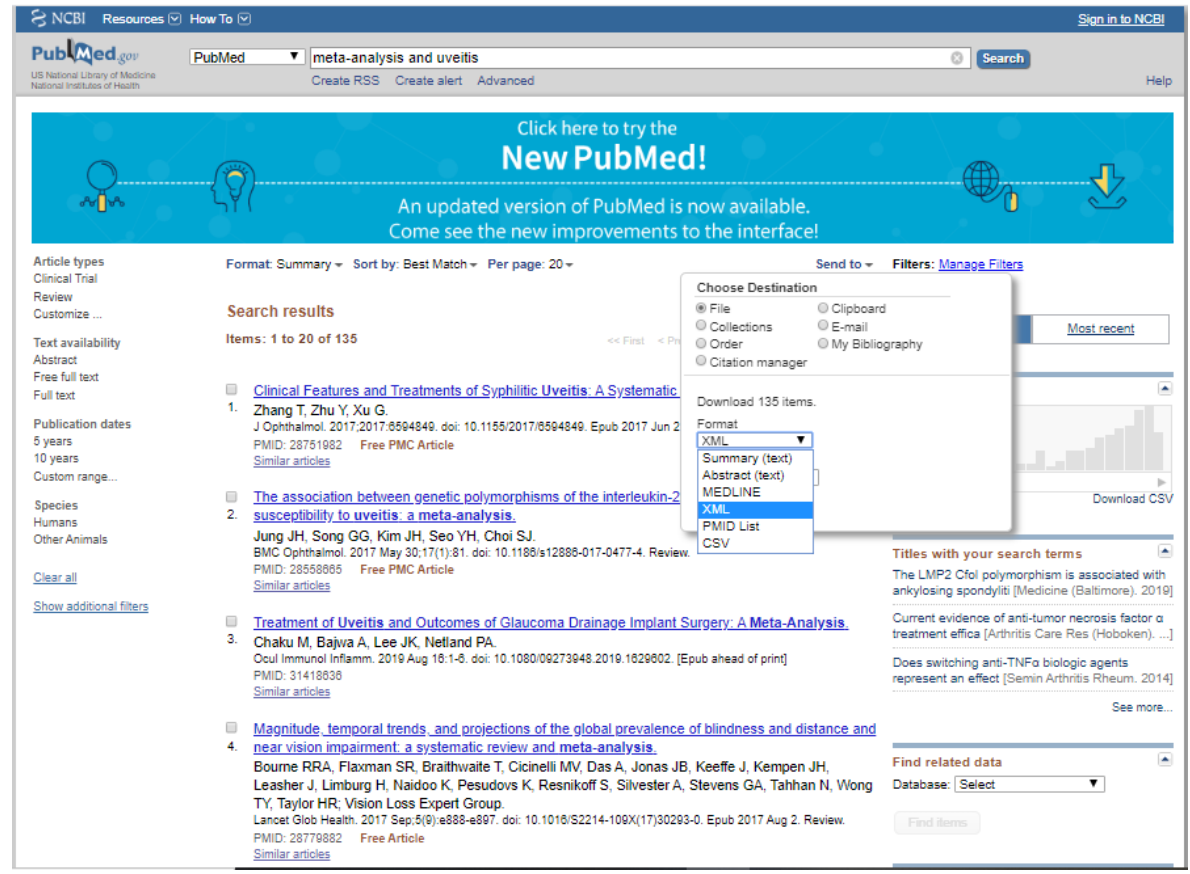

Já no Rayyan basta clicar em "select files" e abrir a pasta downloads para que os artigos sejam importados para o aplicativo. (Figura 2)

Após este processo, pode-se prosseguir com a seleção dos artigos.

A estruturação do aplicativo possibilita a separação dos idiomas dos artigos que foram importados assim como do tipo de estudo realizado, além da revista em que houve a publicação e do ano em que ocorreu. (Figura 3)

Os critérios de inclusão utilizados para esse trabalho foram: artigos publicados de 1 de janeiro 1999 a 30 de setembro de 2020 em inglês ou português, revisões sistemáticas com meta-análise, guidelines, painel de especialistas e artigos originais comparando diferentes drogas para 0 tratamento das uveítes não infecciosas.

Já os critérios de exclusão foram: revisões narrativas, relatos de caso, artigos cujo tratamento foi realizado em animais ou in vitro, artigos que abordam doenças infecciosas, artigos em que não consta o resumo e artigos cujo objetivo principal não estava relacionado com manejo ou tratamento das doenças selecionadas no processo de busca do trabalho. 
Figura 2- Exemplo de como realizar a importação de artigos no aplicativo Rayyan.

$\leftarrow \rightarrow \mathrm{C} \quad$ rayyan.qcri.org/reviews/108861/searches/new

New search for Review: meta-analysis and uveitis

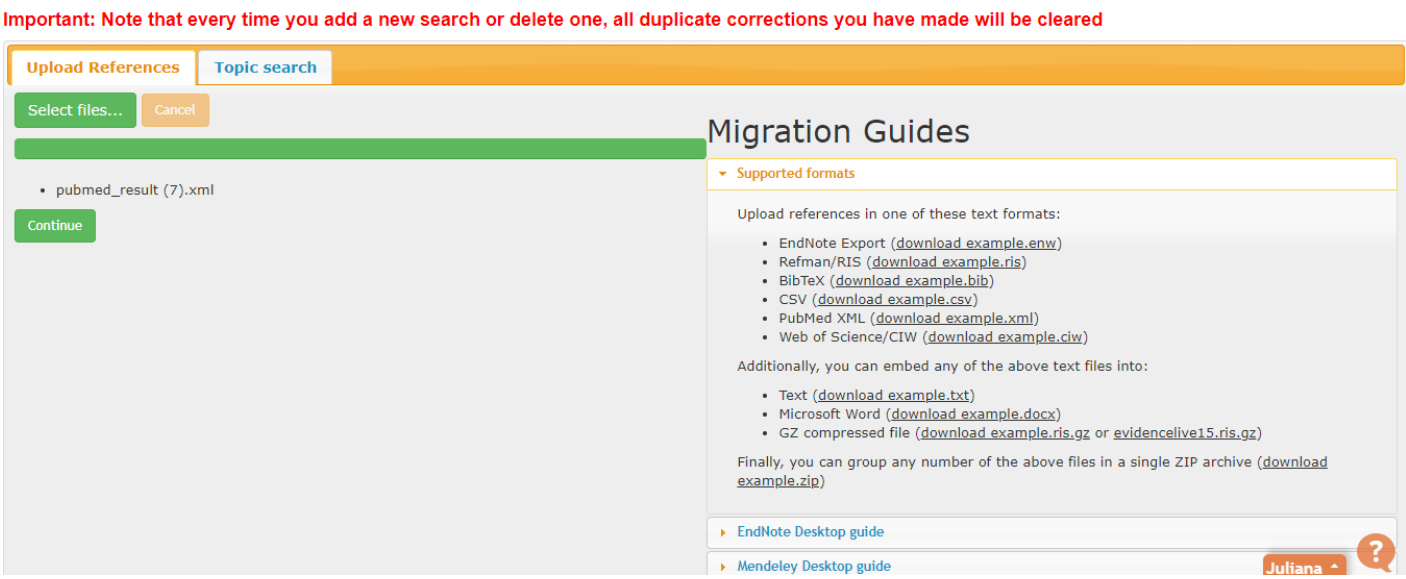

Figura 3- Exemplo da estrutura do aplicativo Rayyan.

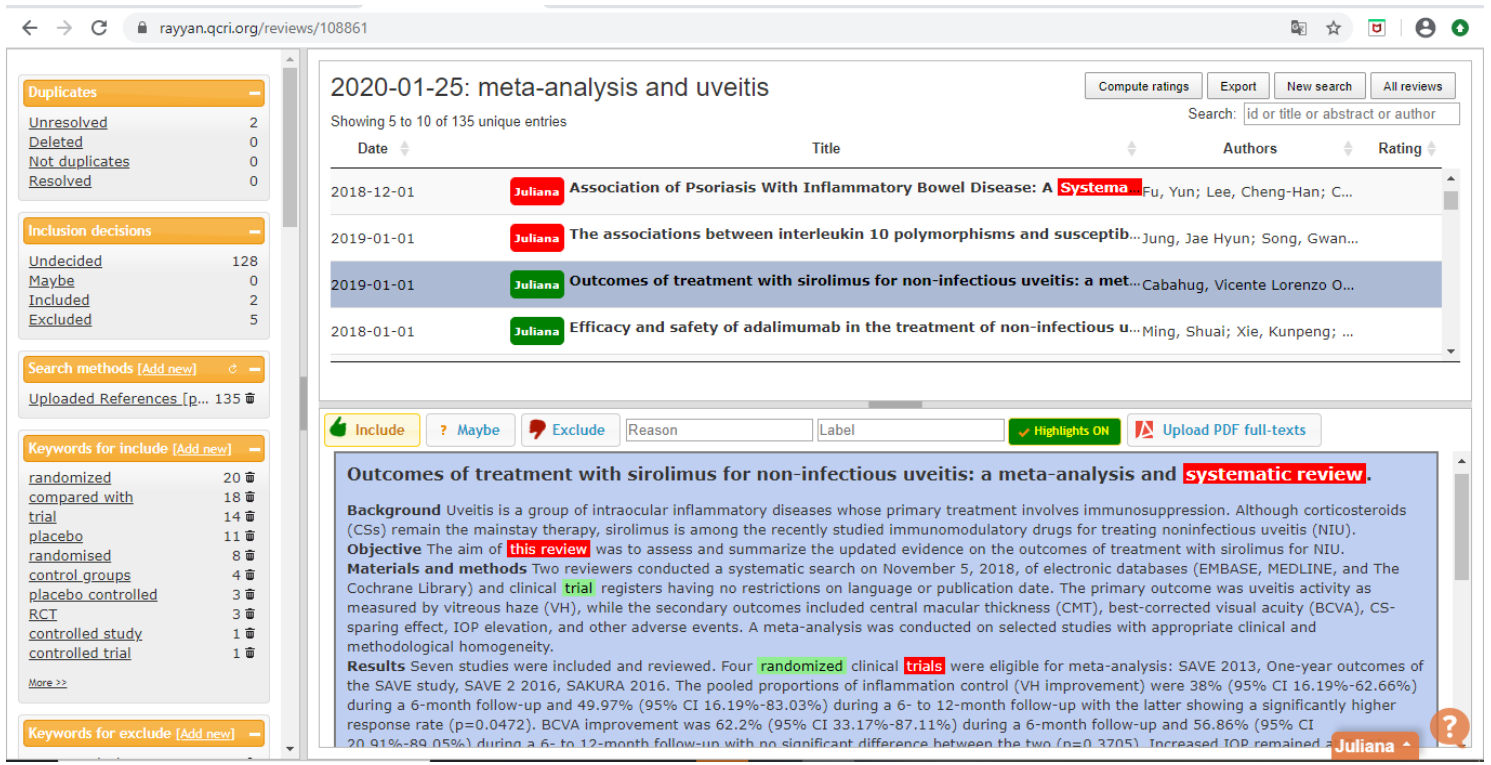

Então, criou-se o resumo das doenças selecionadas no processo de busca, no qual constam, entre outros: definição, diagnóstico, diagnóstico 
diferencial e tratamento. Para seu embasamento foram utilizados updates recentes.

Em relação ao resumo das doenças, quando encontrados artigos que divergiam de condutas terapêuticas, utilizou-se o Pubmed para a busca de meta-análises que pudessem sanar a dúvida. Por outro lado, nos casos em que não se encontrou meta-análises, a fundamentação ocorreu tanto através das opiniões dos especialistas, como também da realidade do país, pois algumas medicações não estão disponíveis no mercado, resultando na diminuição de tratamentos possíveis.

Concluídos os resumos, passou-se para a fase de estruturação dos fluxogramas das doenças. Para isso, elaboraram-se dois modelos padrão. $O$ primeiro, relacionado à divisão de setores em acometimento do segmento anterior e do segmento posterior, e o segundo, relacionado à lateralidade. Feito isso, adotou-se as medidas de forma sucessiva, conforme ilustrado nos fluxogramas. Vale ressaltar que as uveíte anterior idiopáticas, esclerite, artrite idiopática juvenil e Vogt-Koyanagi-Harada não se enquadraram nos modelos padrão acima referidos. 


\subsection{Resumos das drogas mais utilizadas em uveítes não infecciosas}

O objetivo de criar os resumos das drogas deve-se a necessidade de acrescentar informações relevantes que não caberiam nos fluxogramas, pois 0 intuito do trabalho é deixa-los de forma mais direta e objetiva, facilitando a sua análise.

Primeiramente, deve-se esclarecer que foram elaborados os resumos de apenas três drogas, que são: metotrexato, azatioprina e adalimumab. Isso porque utilizou-se como critério aquelas mais usadas para tratar as uveítes não infecciosas.

Para a revisão bibliográfica dessas medicações foram utilizados os guidelines e os artigos já triados no processo de busca do item 2 dos objetivos.

Já na elaboração dos mencionados resumos, vale destacar que em relação às drogas imunossupressoras constam os seguintes tópicos: apresentação da medicação, mecanismo de ação, dosagem máxima, posologia, efeitos colaterais, dose de manutenção, além da duração dos retornos para as consultas subsequentes. 


\section{Resultados}

\subsection{Criação dos fluxogramas de investigação}

Em relação às buscas realizadas nas páginas eletrônicas da AAO (8), SBU(10) e CBO(11), não foram identificados protocolos que se enquadrassem na pesquisa. Contudo, o trabalho apoiou-se no livro da AAO (13), nos Protocolos Clínicos e Diretrizes Terapêuticas (PCDT) em uveítes posteriores não infecciosas no sítio do Ministério da Saúde (http://saude.gov.br/protocolose-diretrizes) bem como na opinião dos especialistas do ambulatório. (11)

Como já foi dito acima, para a composição dos fluxogramas foram escolhidas as doenças com base no estudo de Gonzalez e colaboradores.(14)

Foram elaborados quatro fluxogramas de acordo com a classificação anatômica. O primeiro deles foi o de uveíte anterior, que apresenta cinco doenças: uveíte anterior idiopática, herpes, ciclite heterocrômica de Fuchs, artrite juvenil idiopática e as espondiloartropatias axiais (Figura 4). É importante ressaltar que em todos os quatros fluxogramas, foi criado uma subdivisão, na qual contam as outras doenças que devem ser lembradas como causadoras de uveíte.

No fluxograma de uveíte posterior (Figura 5), bem como no de uveíte intermediária, (Figura 6) há cinco doenças. No primeiro, são as seguintes: toxoplasmose, sífilis, tuberculose, Behçet e sarcoidose. Já no segundo, tem-se: pars planite, sífilis, sarcoidose, tuberculose e síndrome mascarada. Nota-se que a síndrome mascarada está inclusa na secção outras do fluxograma de uveíte posterior.

Por último, o fluxograma de panuveíte (Figura 7) é composto por: toxoplasmose, sífilis, tuberculose, Vogt-Koyanagi-Harada/oftalmia simpática, Behçet e sarcoidose. 
Figura 4- Fluxograma de condutas nas causas mais frequentes de uveíte anterior.

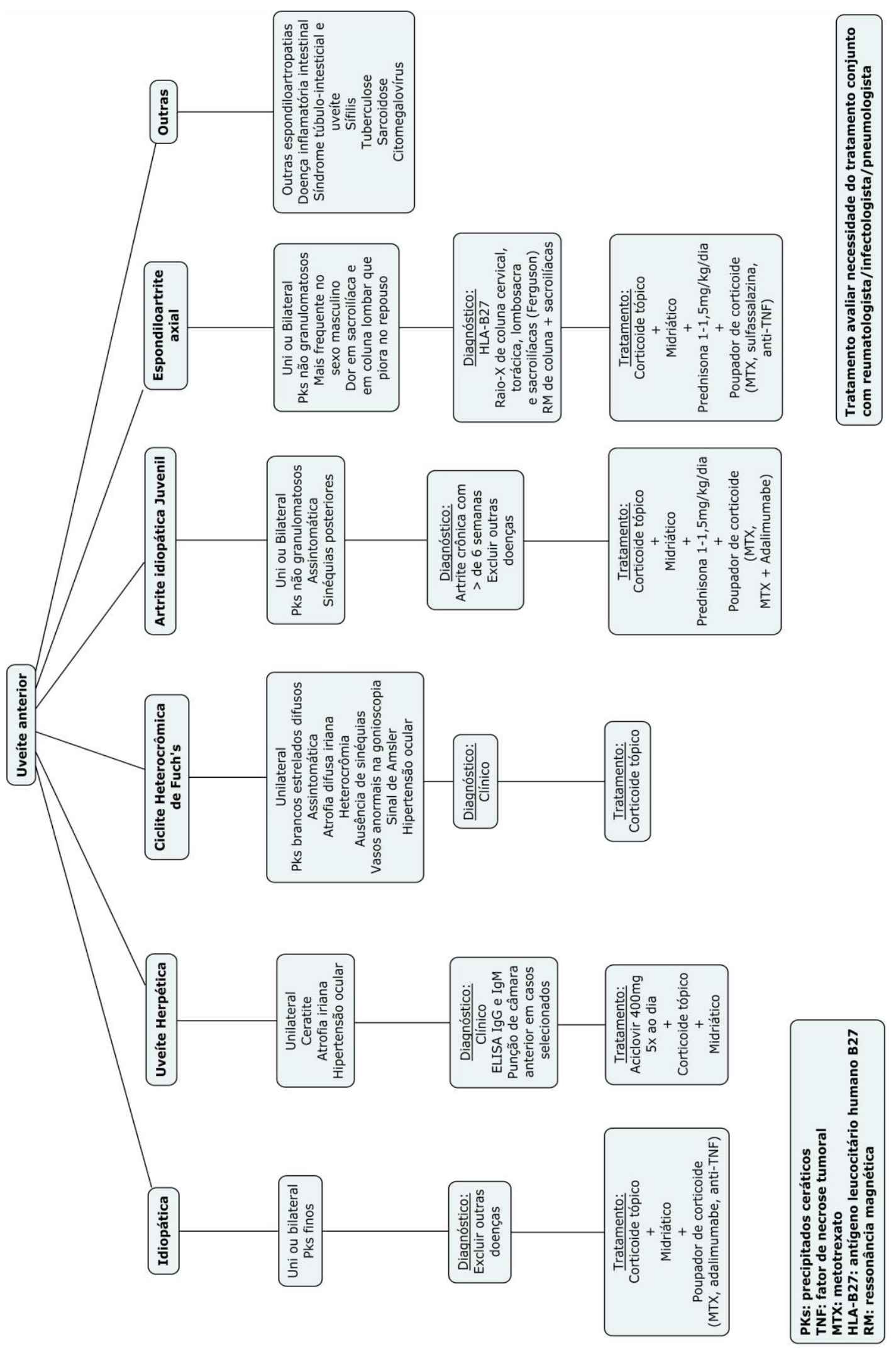


Figura 5- Fluxograma de condutas nas causas mais frequentes de uveíte posterior.
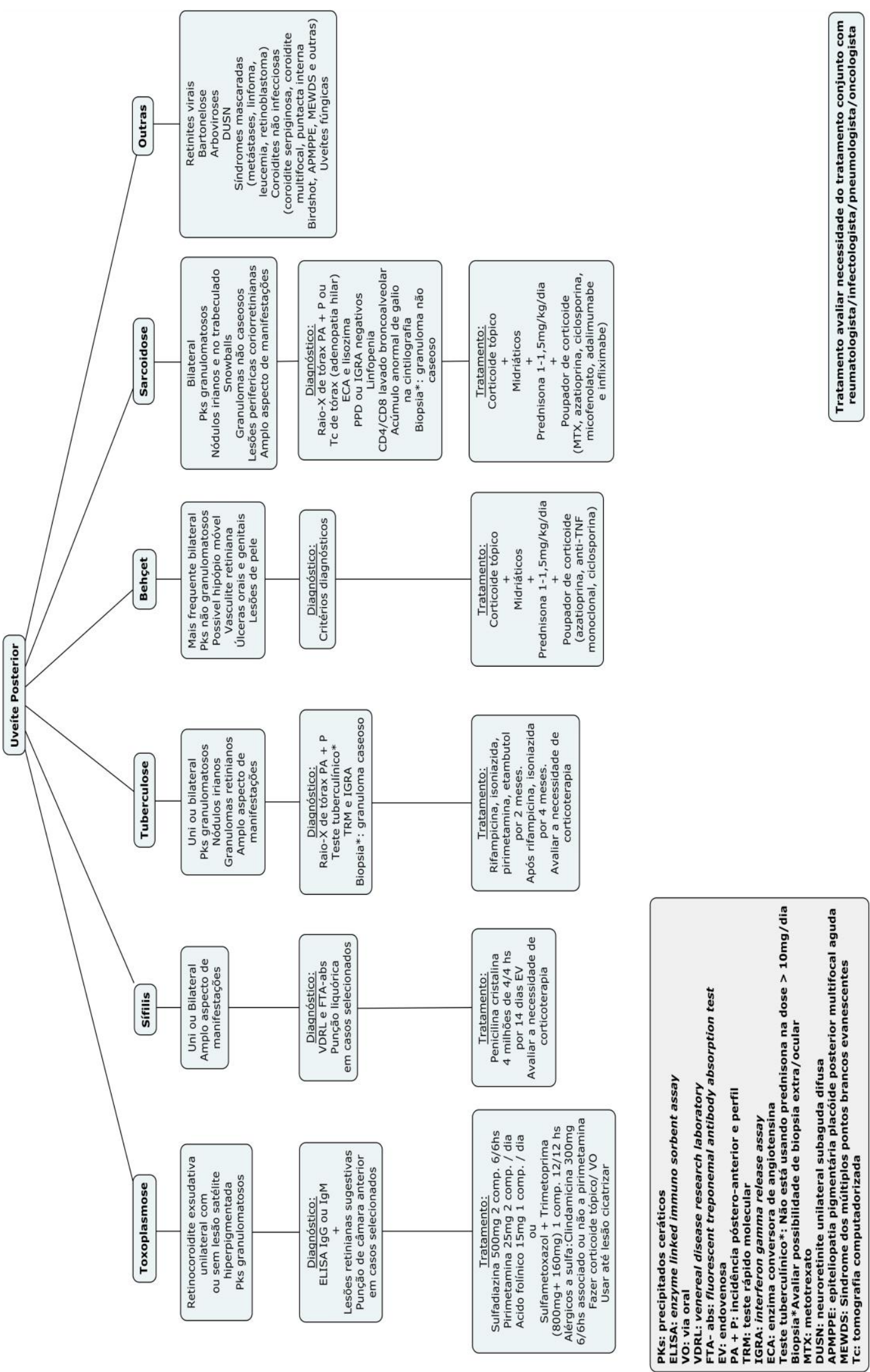
Figura 6: Fluxograma de condutas nas causas mais frequentes de uveíte intermediária.
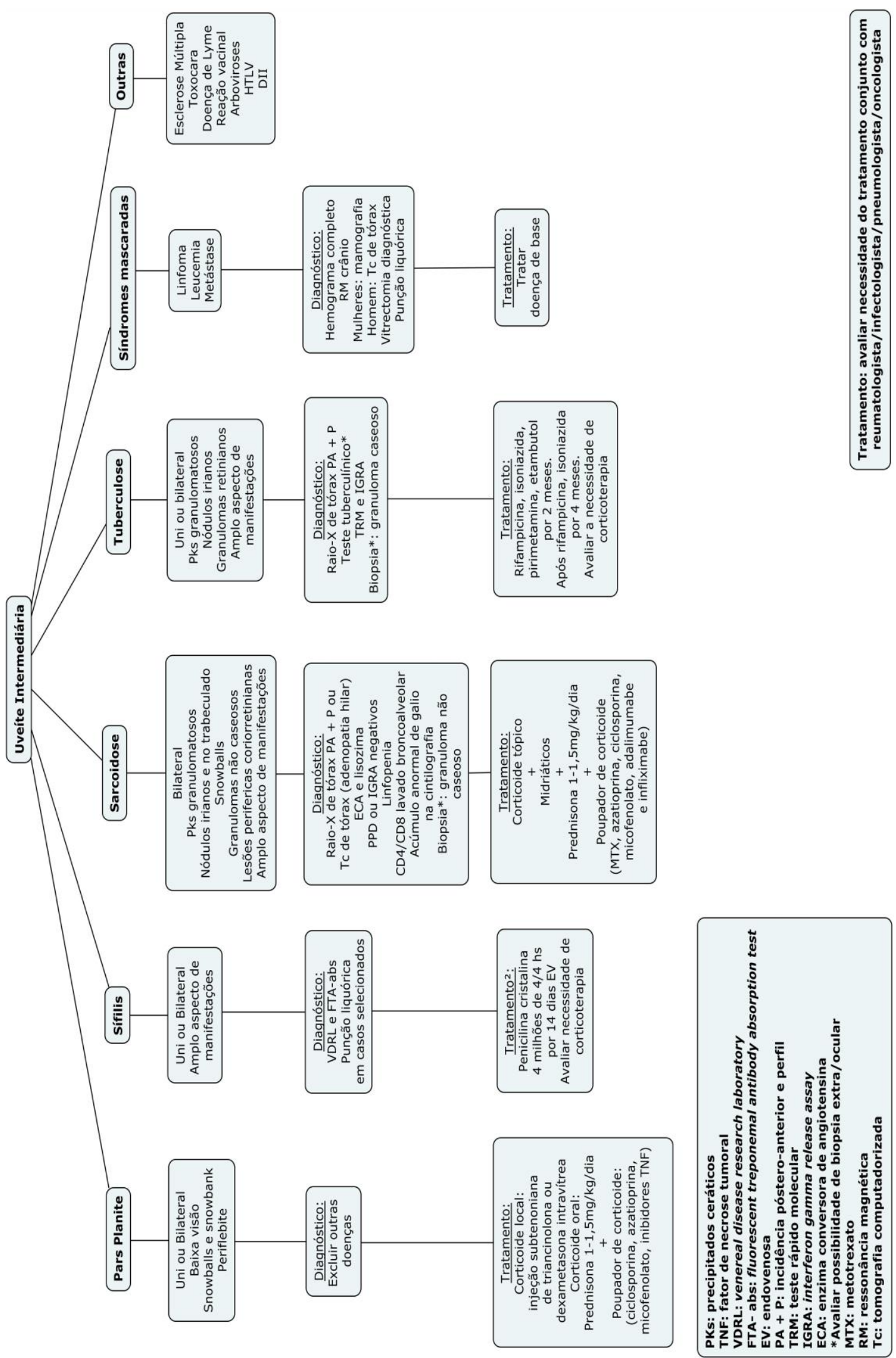
Figura 7: Fluxograma de condutas nas causas mais frequentes de panuveíte
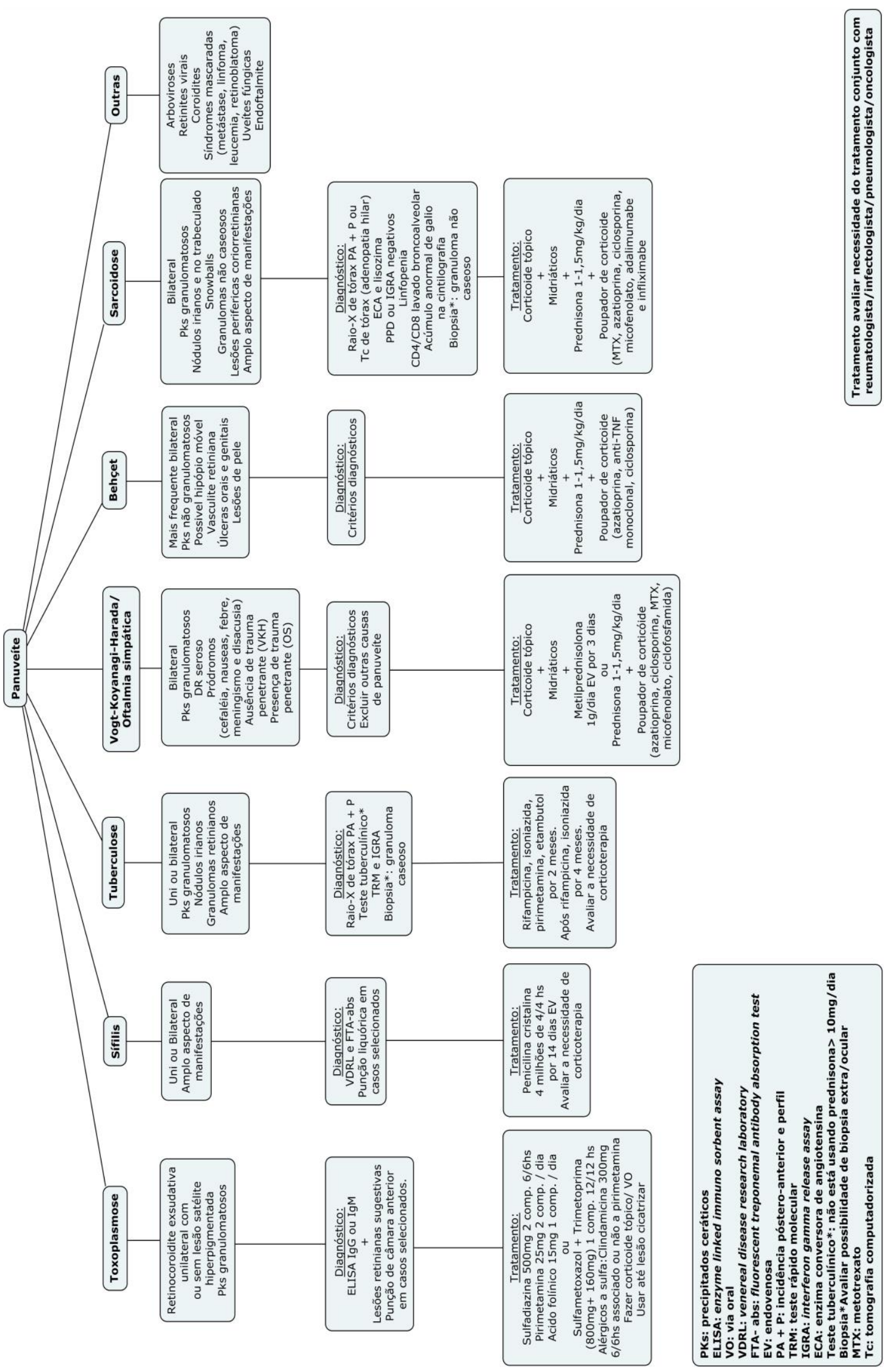


\subsection{Criação dos fluxogramas de condutas terapêuticas das principais uveítes não infecciosas.}

Na primeira busca foram encontrados 3.886 artigos, sendo 448 filtrados para a revisão e elaboração dos fluxogramas. O termo de busca que apresentou mais artigos na triagem foi "immunossuppressive therapy and uveitis", com 1840 artigos encontrados no Pubmed. Porém, apenas 244 deles enquadravam-se nos critérios de inclusão do trabalho. A quantidade de artigos com os outros termos de busca pode ser visualizada na tabela 1, que segue abaixo.

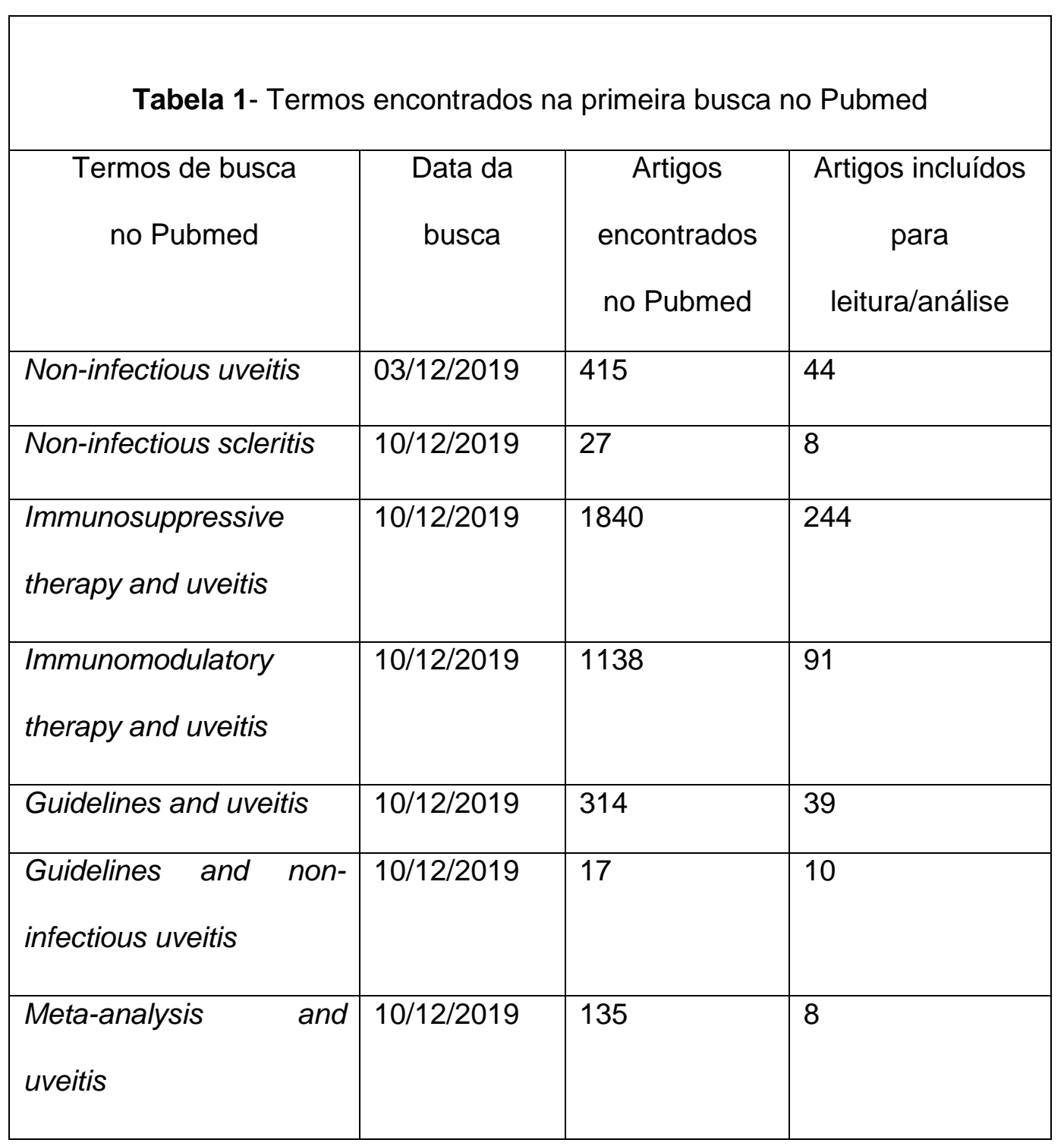


Deve-se entender que a busca dos artigos foi realizada através das palavras-chave, razão pela qual alguns artigos encontrados foram contados mais de uma vez. Como exemplo, todos os 10 artigos encontrados na busca Guidelines and non-infectious uveitis também foram encontrados na busca de Guidelines and uveitis, e assim por diante.

Consequentemente, esses artigos foram utilizados para a composição dos fluxogramas de condutas terapêuticas das principais uveítes não infecciosas e para elaboração dos resumos das doenças.

Já na segunda busca, foram encontrados 9940 artigos, dos quais 138 foram triados para análise, conforme consta na tabela 2.

\begin{tabular}{|l|l|l|l|}
\hline \multicolumn{4}{|c|}{ Tabela 2- Termos encontrados na segunda busca no Pubmed } \\
\hline \multicolumn{1}{|c|}{ Pubmed } & $\begin{array}{c}\text { Artigos } \\
\text { encontrados no } \\
\text { Pubmed }\end{array}$ & $\begin{array}{c}\text { Artigos incluídos } \\
\text { para } \\
\text { leitura/análise }\end{array}$ \\
\hline Vogt-Koyanagi-Harada & $30 / 09 / 2020$ & 1005 & 17 \\
\hline Sympathetic opthalmia & $30 / 09 / 20 / 20$ & 322 & 1 \\
\hline $\begin{array}{l}\text { Juvenile idiopathic arthritis } \\
\text { associated uveitis }\end{array}$ & $30 / 09 / 20 / 20$ & 590 & 51 \\
\hline Behçet uveitis & $30 / 09 / 20 / 20$ & 6074 & 15 \\
\hline Ocular sarcoidosis uveitis & $30 / 09 / 20 / 20$ & 413 & 14 \\
\hline Idiopathic scleritis & $30 / 09 / 20 / 20$ & 101 & 7 \\
\hline Pars planitis & $30 / 09 / 20 / 20$ & 193 & 8 \\
\hline Uveitis HLA-B27 & $30 / 09 / 20 / 20$ & 648 & 15 \\
\hline Idiopathic anterior uveitis & $30 / 09 / 2020$ & 594 & 10 \\
\hline
\end{tabular}

Além disso, após o término de cada fluxograma, fez-se uma nova procura no Pubmed em relação a cada doença, de forma a averiguar se havia 
algum artigo importante publicado recentemente para ser acrescentado ao trabalho.

Dessa forma, a primeira doença analisada foi artrite idiopática juvenil. Durante a sua busca foram selecionados para análise 51 artigos. Porém, para a elaboração do respectivo fluxograma, foram utilizados 13 artigos. Essa escolha deu-se em razão do grande número de artigos encontrados e, como já existe padronizações para condutas nessa doença, decidiu-se por priorizar os guidelines e os consensos.

Após a criação do fluxograma e do resumo, coube a equipe do IURE, ao orientador e aos demais colaboradores deste trabalho fazer a verificação e análise, o que resultou em algumas modificações (Figura 8)

Já a segunda doença analisada foi Behçet. Foram achados 6074 artigos, dos quais foram analisados 8 artigos, pois, semelhante a artrite idiopática juvenil, já existem condutas pré-determinadas, sendo o fluxograma baseado principalmente nas recomendações do European League Against Rheumatism (EULAR) (17) (Figura 9).

A terceira doença foi sarcoidose. Encontraram-se mais de 1000 artigos ao se realizar a busca com as palavras-chave sarcoidosis uveitis, razão pela qual foi acrescentada a palavra ocular. Então, foram filtrados no sítio do Pubmed 413 artigos, dos quais 14 foram triados com base nos critérios de inclusão do trabalho (Figura 10).

A quarta doença foi a esclerite idiopática. Em relação a ela, foram encontrados 101 artigos, dos quais 13 foram analisados. Destes, 5 artigos são da primeira busca e 7, da segunda (Figura 11).

O quinto fluxograma foi sobre pars planite. Nele verificaram-se 193 artigos no Pubmed, sendo 9 deles triados e analisados. Pelo menos 3 artigos se repetiam em relação a conduta no tratamento. Dessa forma, escolheu-se os dois mais recentes para enquadrar na bibliografia (Figura 12).

O sexto e o sétimo fluxogramas foram respectivamente uveíte por HLAB27 e uveíte anterior idiopática. No primeiro, observou-se um total de 648 artigos no Pubmed, sendo 15 analisados para a elaboração do fluxograma. Em 
relação ao segundo, 615 artigos foram achados. Desses, 10 foram para a leitura para compor o fluxograma (Figura 13).

O último fluxograma a ser realizado foi sobre Vogt-Koyanagi-Harada. Foram encontrados 1005 artigos, sendo 36 triados para análise (Figura 14).

Observam-se abaixo os respectivos fluxogramas. Logo depois, segue o resumo das doenças. 
Figura 8: Fluxograma de condutas para tratamento da AlJ.
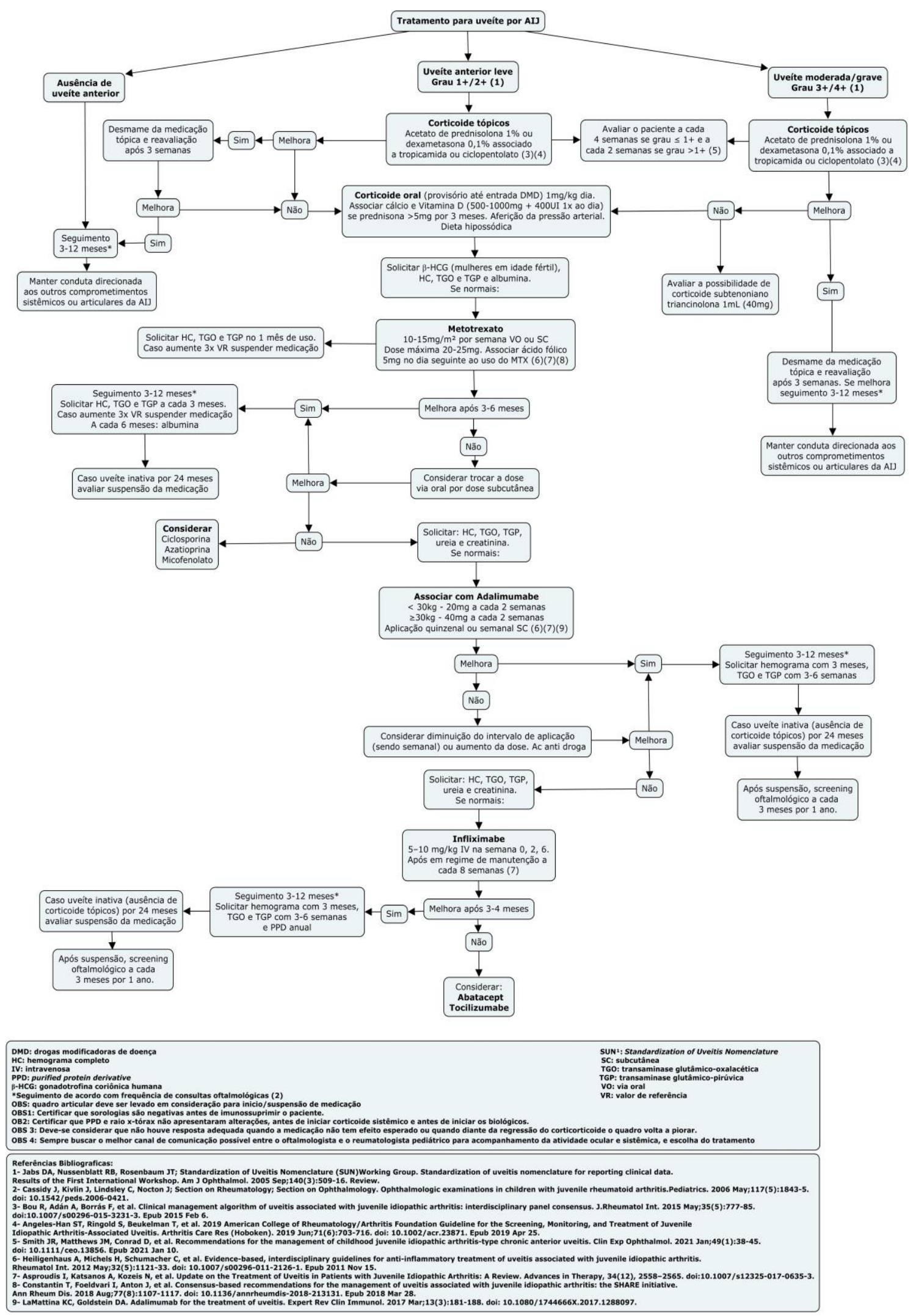
Figura 9: Fluxograma de condutas para tratamento de Behçet.

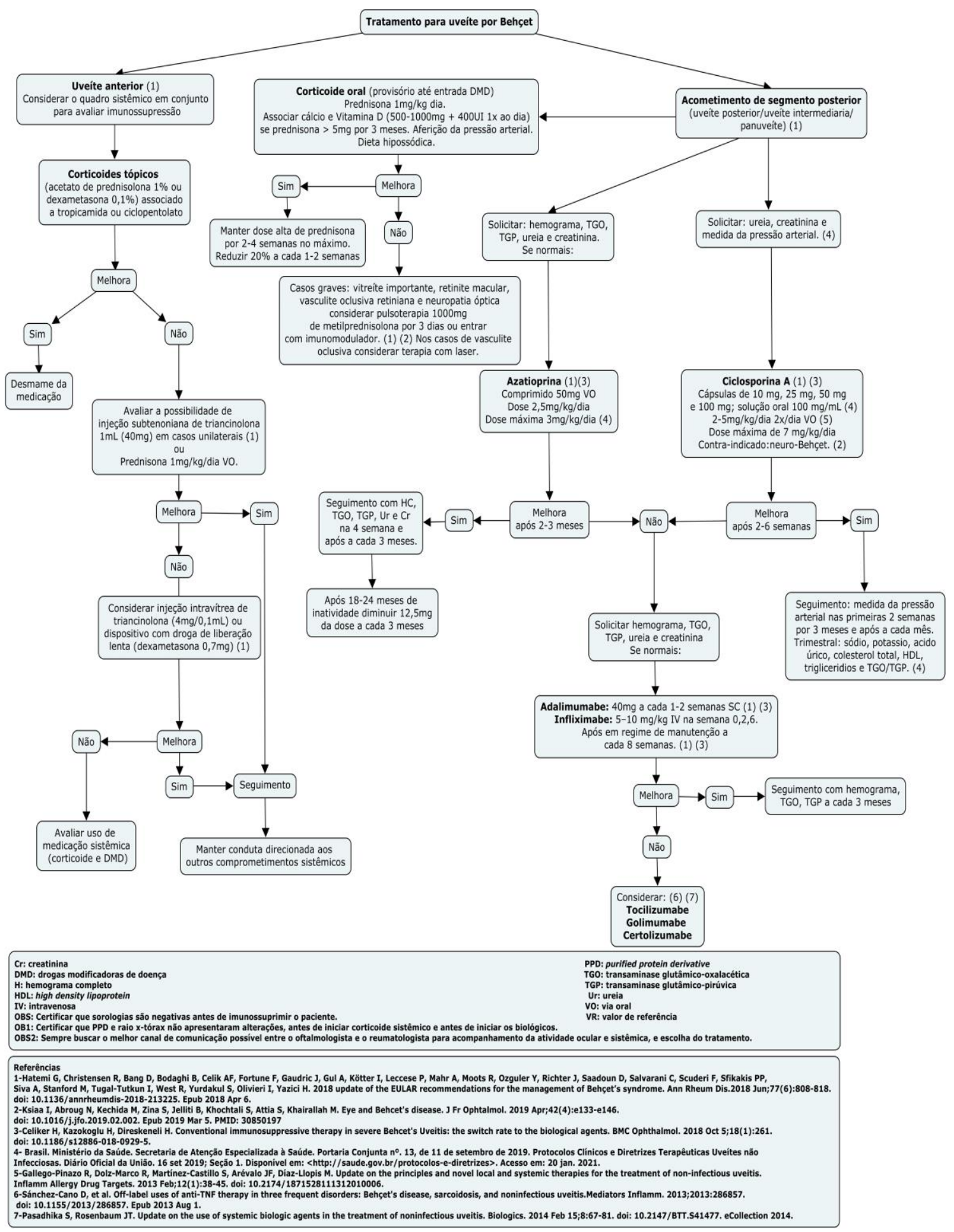


Figura 10: Fluxograma de condutas para tratamento da sarcoidose.

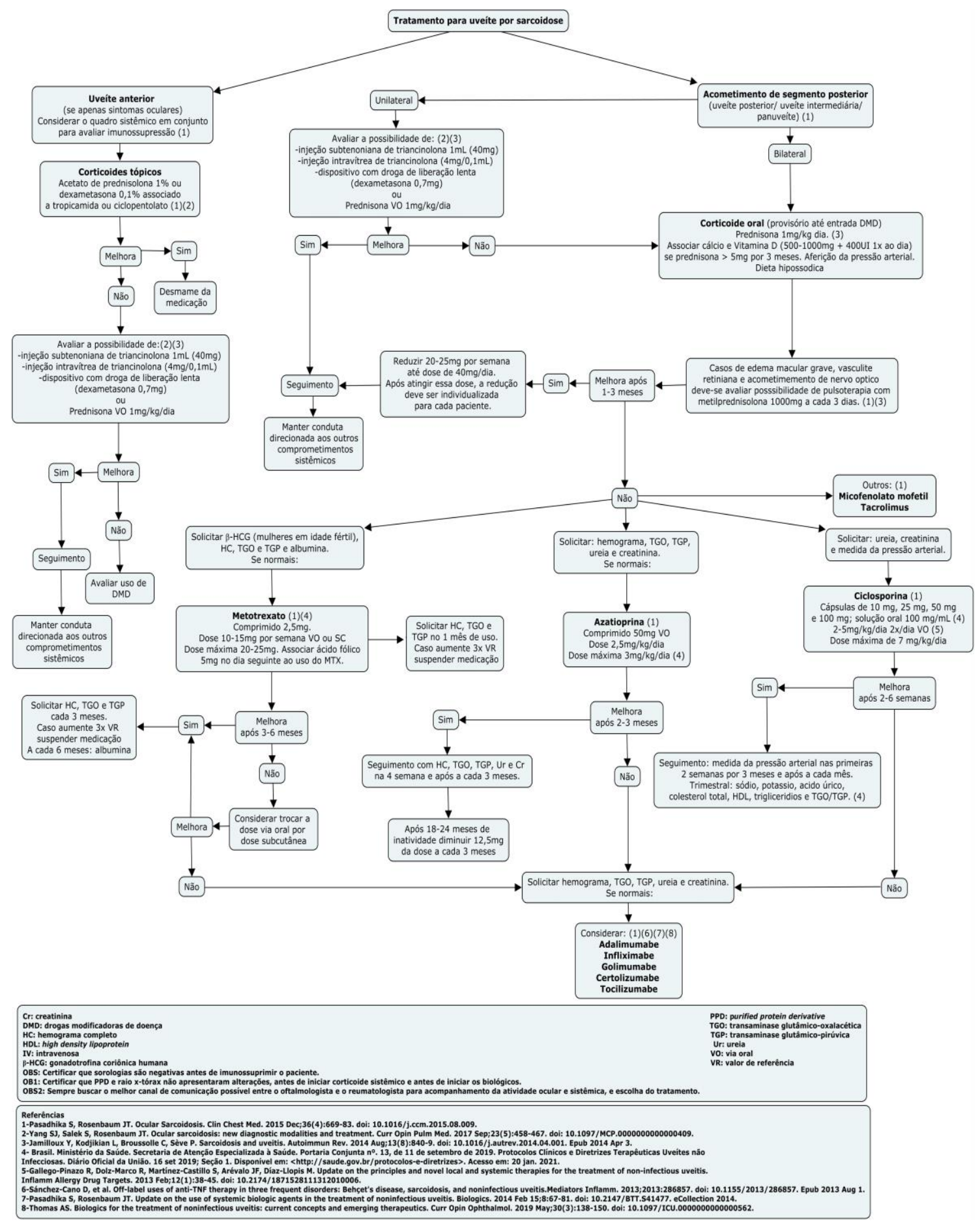


Figura 11: Fluxograma de condutas para tratamento da esclerite não infecciosa.
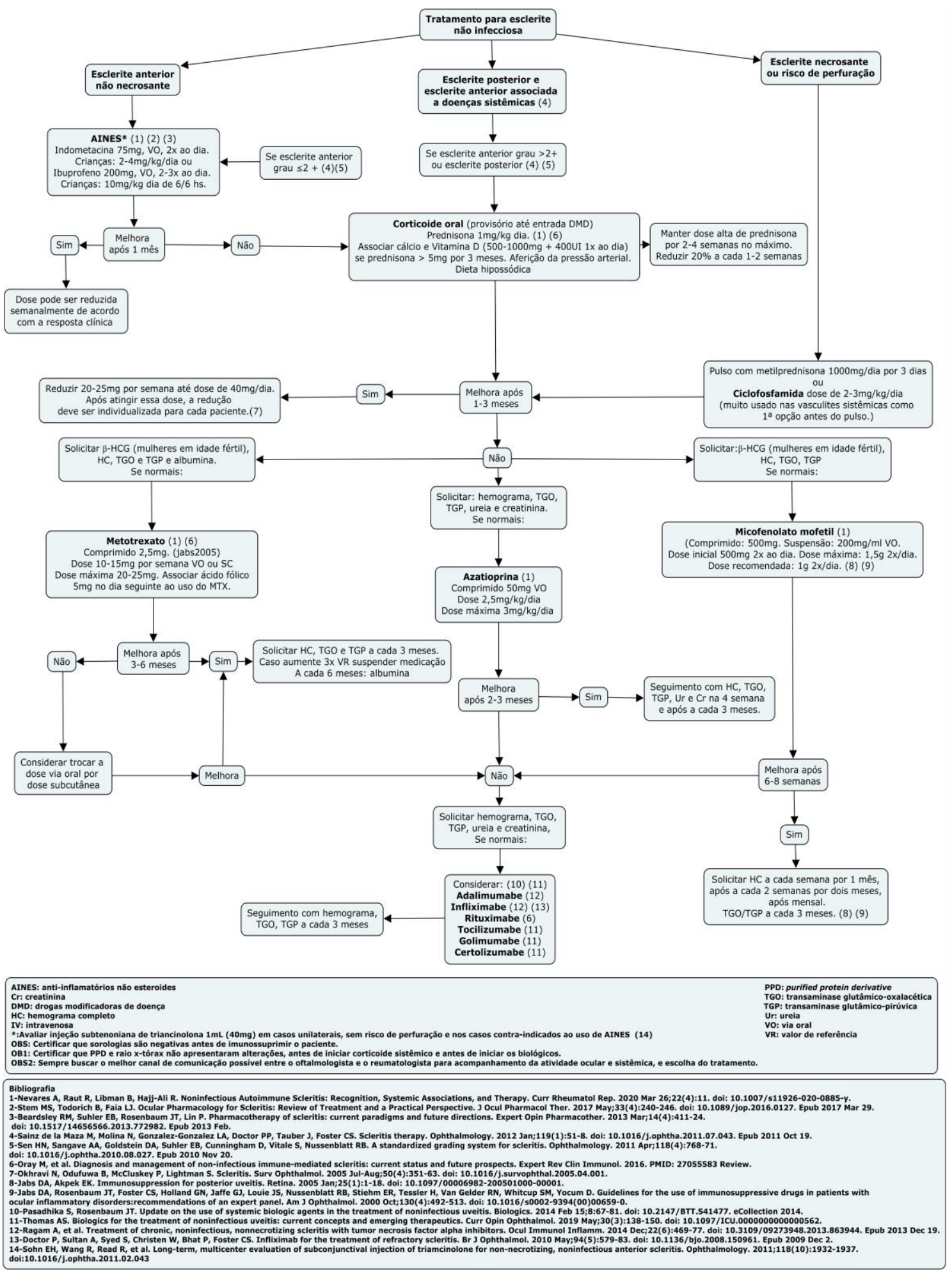
Figura 12: Fluxograma de condutas para tratamento da pars planite.

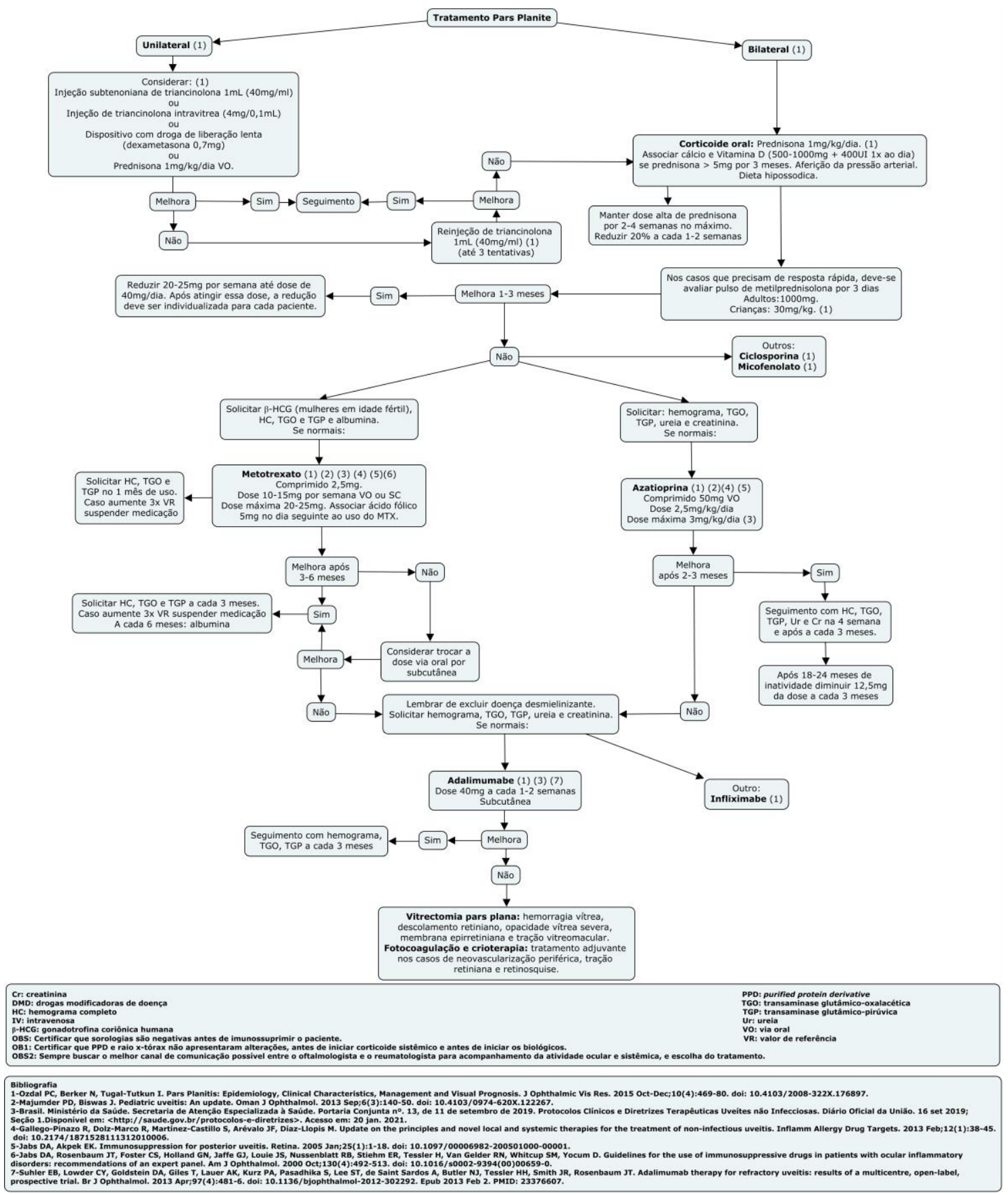


Figura 13: Fluxograma de condutas para tratamento HLA-B27/espondiloartroartrites.

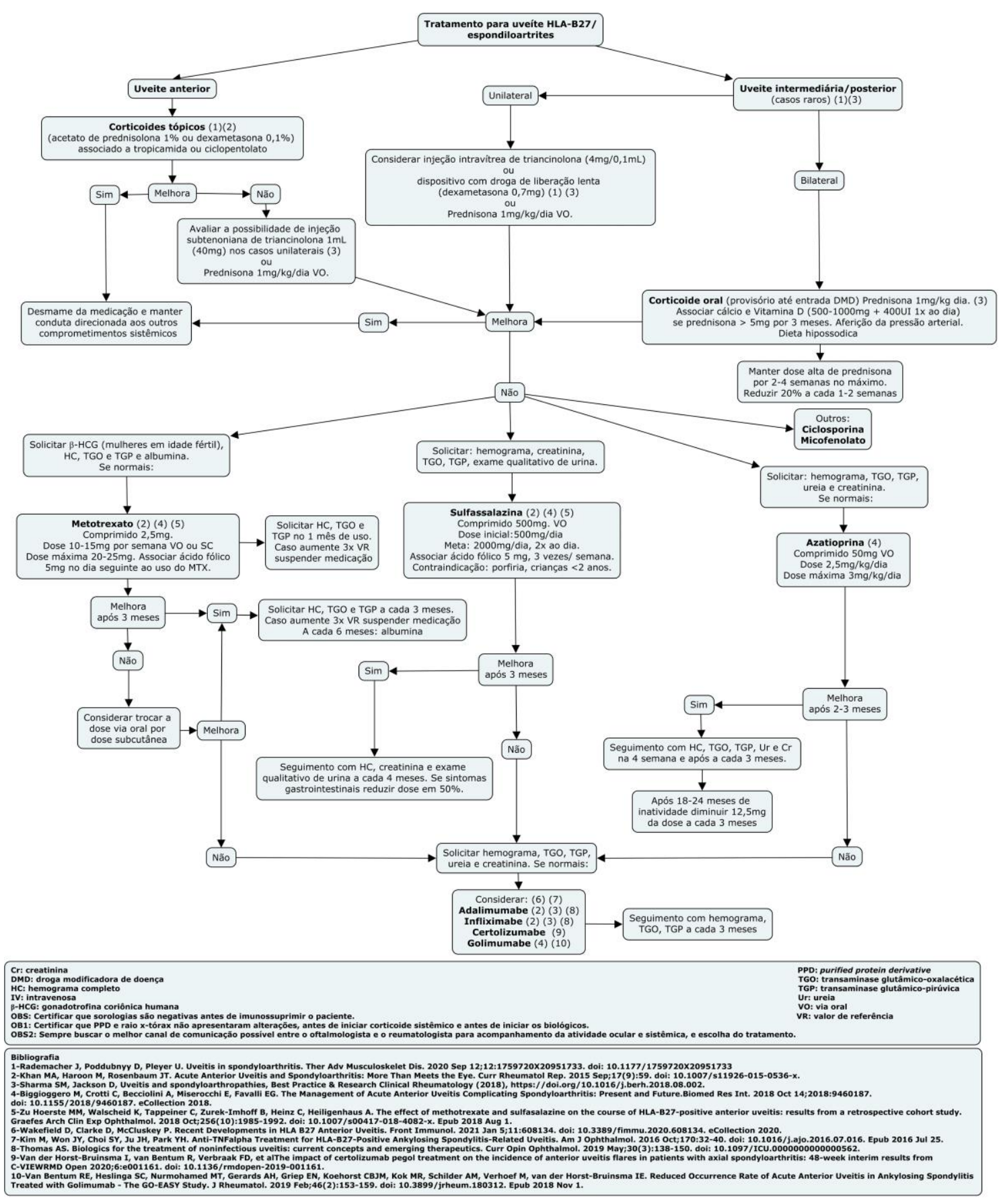


Figura 14: Fluxograma de condutas para tratamento da uveíte anterior idiopática.

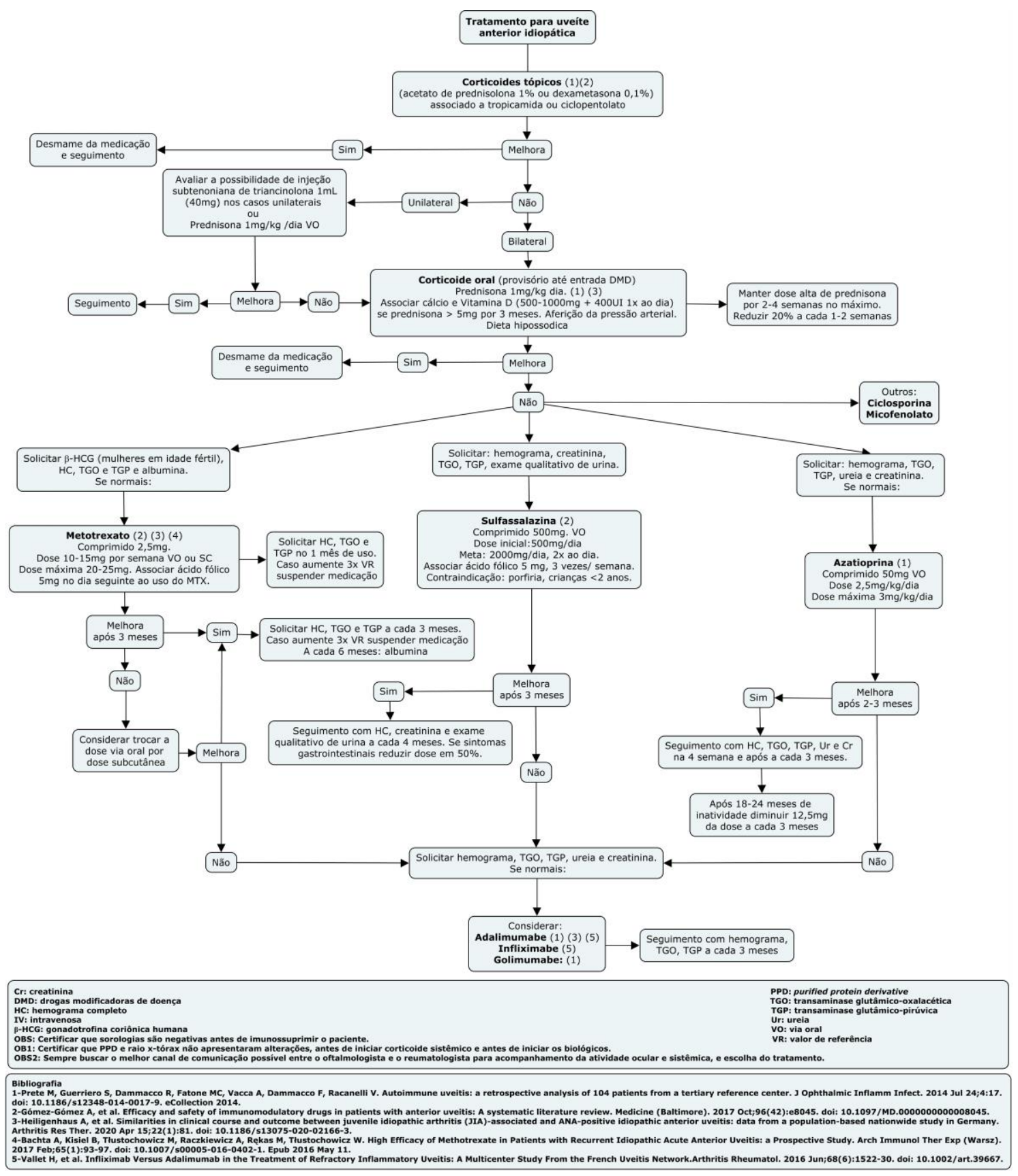


Figura 15: Fluxograma de condutas para tratamento de Vogt-Koyanagi-Harada.
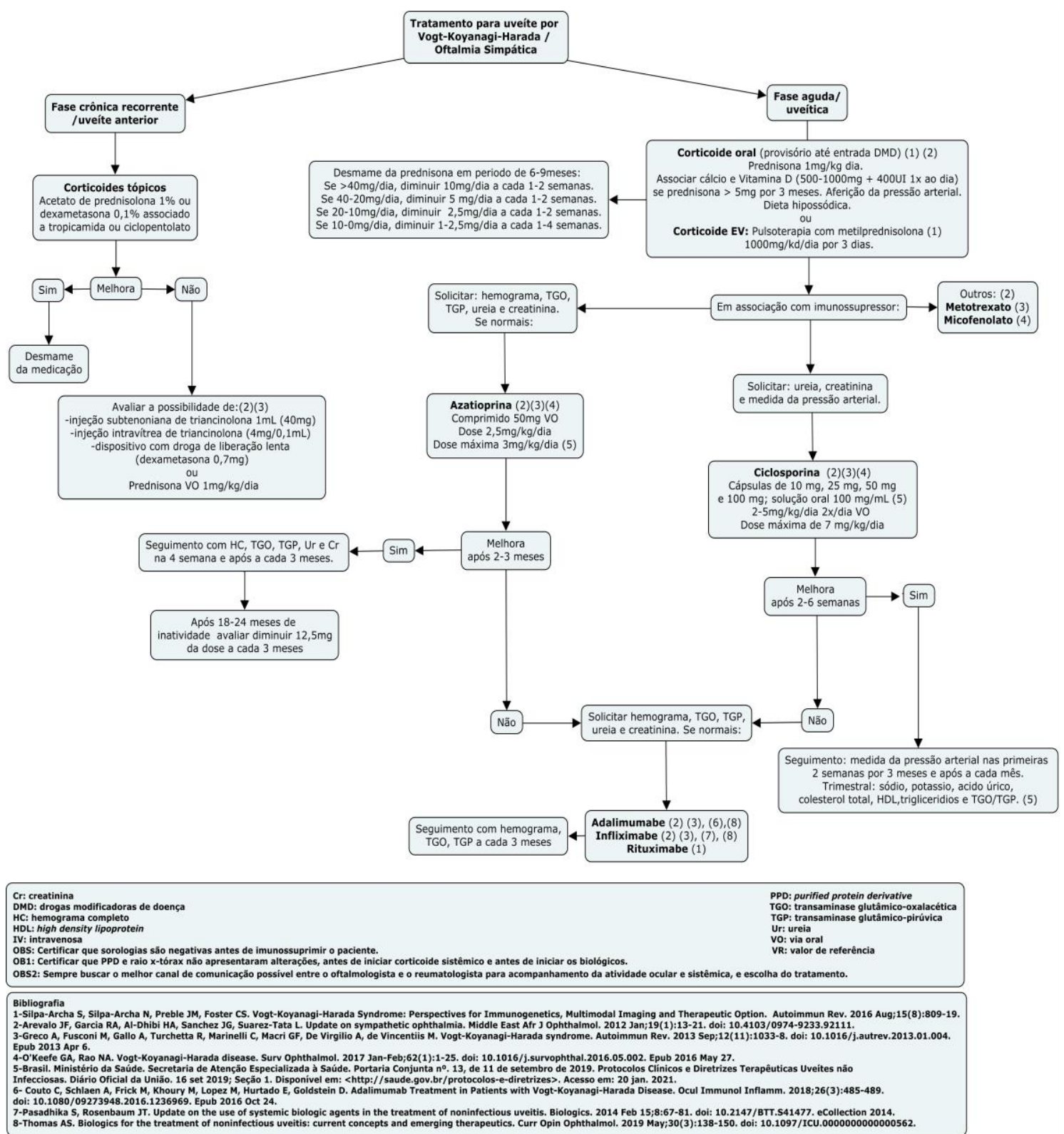


\subsubsection{Resumo Artrite Idiopática Juvenil}

Doença autoimune caracterizada por artrite crônica com uma duração maior que seis semanas e com inicio dos sintomas antes dos 16 anos.(18)

Diagnóstico ocular: uveíte anterior, bilateral, crônica e silenciosa.(19)

Investigação: diagnóstico de exclusão.

Prognostico: fator antinuclear (FAN), fator reumatoide (FR).

Diagnóstico Diferencial: sarcoidose, Vogt-Koyanagi-Harada, Behçet, nefrite túbulo-intersticial, oftalmia simpática, uveíte herpética e uveíte idiopática.

Monitoramento: após diagnóstico de AlJ todas as crianças devem passar por avaliação oftalmológica no primeiro mês, (20) com seguimento de acordo com a tabela 3.

\begin{tabular}{|c|c|c|c|c|c|}
\hline Tipo & FAN & $\begin{array}{l}\text { Idade de } \\
\text { inicio }\end{array}$ & $\begin{array}{l}\text { Duração } \\
\text { da doença }\end{array}$ & Risco & $\begin{array}{l}\text { Frequência } \\
\text { consultas }\end{array}$ \\
\hline \multirow{8}{*}{$\begin{array}{l}\text { Oligoartrite } \\
\text { ( } \leq 4 \\
\text { articulações/ } \\
\text { poliartrite(>4 } \\
\text { articulações) }\end{array}$} & + & $\leq 6$ anos & $\leq 4$ anos & Alto & 3 meses \\
\hline & + & $\leq 6$ anos & $>4$ anos & Moderado & 6 meses \\
\hline & + & $\leq 6$ anos & $>7$ anos & Baixo & 12 meses \\
\hline & + & $>6$ anos & $\leq 4$ anos & Moderado & 6 meses \\
\hline & + & $>6$ anos & $>4$ anos & Baixo & 12 meses \\
\hline & - & $\leq 6$ anos & $\leq 4$ anos & Moderado & 6 meses \\
\hline & - & $\leq 6$ anos & $>4$ anos & Baixo & 12 meses \\
\hline & - & $>6$ anos & SA & Baixo & 12 meses \\
\hline $\begin{array}{l}\text { Doença de } \\
\text { Still }\end{array}$ & SA & SA & SA & Baixo & 12 meses \\
\hline
\end{tabular}

Abreviação: SA, sem aplicação.

Cassidy J, Kivlin J, Lindsley C, Nocton J; Section on Rheumatology; Section on Ophthalmology. Ophtalmologic examinations in children with juvenile rheumatoid arthritis. Pediatrics. 2006 May; 117(5): 1843-5.(21)

\section{Tratamento:}

Tópico: corticoides (dexametasona $0,1 \%$ ou acetado de prednisolona $1 \%$ ) e cicloplégicos (tropicamida ou ciclopentolato).

Sistêmicos: corticoide oral $1 \mathrm{mg} / \mathrm{kg} / \mathrm{dia}$ nos casos mais graves (grau $3+/ 4+) .(5)(11)$ 
Se após duas semanas não houver melhora, avaliar a possibilidade injeção subtenoniana de triancinolona.(20)(22)

Metotrexato (MTX): comprimido de 2,5mg. Solução injetável de $50 \mathrm{mg}$ e embalagem com 1 frasco-ampola de $2 \mathrm{~mL}$. Solução injetável de $500 \mathrm{mg} \mathrm{e}$ embalagem com 1 frasco-ampola de $20 \mathrm{~mL}$. Dose de 10-15mg/m²por semana via oral ou subcutânea. Tomar 1x/semana. Dose máxima 20-25mg. Suplementação de acido fólico $5 \mathrm{mg}$ no dia seguinte a dose do MTX. (18)(20)(23)

Considerar a troca do uso oral pelo uso subcutâneo quando não houver boa resposta.

\section{Imunobiológicos:}

Adalimumab: associar quando não houver resposta após 3-6 meses de uso do MTX. (24)(25)(26)(27)(28)

Dose: $<30 \mathrm{~kg}$ fazer $20 \mathrm{mg}$ a cada 2 semanas e $\geq 30 \mathrm{~kg}$ fazer $40 \mathrm{mg}$ a cada 2 semanas.(29)

Caso não haja boa resposta, deve-se considerar a diminuição do intervalo de aplicação (sendo semanal) ou aumento da dose.

Infliximab: dose $5-10 \mathrm{mg} / \mathrm{kg}$ por infusão venosa na semana $0,2,6$. Dose de manutenção a cada 4-8 semanas.(20)(23)

Outros: abatacept, tocilizumab (boa resposta ao edema macular refratário), azatioprina, ciclosporina e micofenolato.(19)(23)

Deve-se manter o tratamento por pelo menos 24 meses, após a inatividade da doença. Ao suspender a medicação, é preciso monitorar o paciente a cada 3 meses, pelo período de 1 ano, devido ao risco de recorrência.(19)

Obs: Sempre buscar o melhor canal de comunicação possível entre o oftalmologista e o reumatologista pediátrico para acompanhamento da atividade ocular e sistêmica, e escolha do tratamento. 


\subsubsection{Resumo Behçet}

É uma doença sistêmica crônica, de etiologia desconhecida, que acomete várias partes do corpo, como pele, mucosa, articulação, sistema nervoso, gastrointestinal, artérias, veias e olho. (17)(30)

Diagnóstico: clínico, baseado nas pontuações dos novos critérios internacionais. Considera-se Behçet quando se tem uma pontuação $\geq 4$ pontos. (31)(32)

\begin{tabular}{|l|l|}
\hline Tabela 4. Pontuação para critérios diagnósticos \\
\hline Manifestações clínicas & Pontos \\
\hline Envolvimento ocular & 2 \\
\hline Úlcera oral & 2 \\
\hline Úlcera genital & 2 \\
\hline Lesões de pele & 1 \\
\hline Teste de patergia & 1 \\
\hline Envolvimento vascular & 1 \\
\hline
\end{tabular}

The International Criteria for Behçet's Disease (32)

Diagnóstico ocular: uni ou bilateral, panuveíte não granulomatosa, simétrica ou assimétrica, associada à vasculite retiniana.(31)

Investigação: HLA-B51, teste de patergia e screening para trombofilia.

Diagnóstico Diferencial: sarcoidose, LES (Lúpus Eritematoso Sistêmico), Vogt-Koyanagi-Harada, oftalmia simpática, tuberculose e sífilis.

\section{Tratamento}

Uveíte anterior isolada: corticoides tópicos (dexametasona $0,1 \%$ ou prednisolona 1\%) e cicloplégicos. Em casos refratários e com edema macular persistente, deve-se avaliar a possibilidade de injeção subtenoniana de triancinolona $1 \mathrm{~mL}$ (40mg) ou injeção intravítrea de triancinolona $4 \mathrm{mg} / 0,1 \mathrm{~mL}$ ou droga de liberação lenta (dexametasona $0,7 \mathrm{mg}$ ) ou prednisona $1 \mathrm{mg} / \mathrm{kg} / \mathrm{dia}$.

Os imunossupressores sistêmicos podem ser utilizados para aqueles casos com fatores de mau prognóstico como: idade jovem, sexo masculino e início precoce da doença. (17)

Acometimento de segmento posterior (uveíte intermediária, uveíte posterior e panuveíte): 


\section{Medicações sistêmicas:}

Corticoide oral: prednisona $1 \mathrm{mg} / \mathrm{kg} /$ dia. Provisório até entrada de DMD. (33)(34)

Corticoide EV: pulsoterapia nos casos graves com vitreíte importante, retinite macular, vasculite oclusiva retiniana e neuropatia óptica. (31)

Metilprednisolona: $1000 \mathrm{mg}$ por 3 dias.(11)

\section{Imunossupressores:}

Azatioprina: comprimido $50 \mathrm{mg}$ via oral. Dose $2,5 \mathrm{mg} / \mathrm{kg} / \mathrm{dia}$. Dose máxima $3 \mathrm{mg} / \mathrm{kg} / \mathrm{dia}$.(11) (17)

Ciclosporina A: cápsulas de $10 \mathrm{mg}, 25 \mathrm{mg}, 50 \mathrm{mg}, 100 \mathrm{mg}$ e solução oral 100 $\mathrm{mg} / \mathrm{mL}$. Dose: $2-5 \mathrm{mg} / \mathrm{kg} / \mathrm{dia}$ dividido em duas tomadas.(11)(31)

Dose máxima de $7 \mathrm{mg} / \mathrm{kg} / \mathrm{dia}$. Contra-indicado: neuro-Behçet.(31)

\section{Imunobiológicos:}

Infliximab: dose $5-10 \mathrm{mg} / \mathrm{kg}$ por infusão venosa na semana $0,2,6$. Dose de manutenção a cada 4-8 semanas.(35)

Adalimumab: $40 \mathrm{mg}$ a cada 1-2 semanas. Via subcutânea.(36)

Obs: sempre buscar o melhor canal de comunicação possível entre o oftalmologista e o reumatologista para acompanhamento da atividade ocular e sistêmica, e escolha do tratamento. 


\subsubsection{Resumo Sarcoidose Ocular}

Doença de etiologia desconhecida, crônica, caracterizada pela presença de granulomas não caseosos. Ela pode acometer várias partes do corpo como: pulmão, linfonodos, pele, fígado, olho, dentre outras.(37)(38)(39)(40)

Diagnóstico: manifestações clínicas, imageológicas, histopatológico de granulomas não caseosos e exclusão de doenças granulomatosas.

Diagnóstico ocular: uveíte bilateral e crônica.(41)

Padrão ouro: histopatológico (biopsia), porém é um procedimento muito invasivo com potenciais riscos de complicação.(37)

Dessa forma, o diagnóstico é baseado em sinais clínicos oculares e em resultados de investigações sistêmicas.(42)

Critérios para diagnóstico de sarcoidose ocular baseado no Workshop Internacional (42)

I- Outras causas de uveíte granulomatosa devem ser excluídas.

II-Sinais clínicos de sarcoidose intraocular.

1- Precipitados ceráticos tipo mutton-fat e/ ou nódulos irianos na margem pupilar (Koeppe) ou no estroma (Busacca).

2- Nódulos na malha trabecular e/ ou sinéquia anterior periférica em forma de tenda.

3- Presença de snowballs/ opacidades vítreas em colar de pérolas.

4- Múltiplas lesões periféricas coriorretinianas (ativas e atróficas).

5- Periflebite nodular e/ ou segmentar (pingo de cera) e/ou macroaneurisma em um olho inflamado.

6- Nódulos/granulomas em disco óptico e/ou nódulo coroidal solitário.

7- Bilateralidade (avaliada por exame oftalmológico incluindo imagens oculares que mostram inflamação subclínica).

III-Resultados da investigação sistêmica na suspeita de sarcoidose ocular

1- Linfadenopatia hilar bilateral por radiografia de toráx e/ou pela tomografia computadorizada de toráx.

2- Teste tuberculinico negativo ou Interferon Gama Release Assay (IGRA)

3- Enzima conversora da angiotensina (ECA) sérica elevada

4- Lisozima sérica elevada

5- Razão CD4/CD8 elevada (>3.5) em lavado broncoalveolar 
6- Acúmulo anormal da captação na cintilografia com gálio-67 ou na tomografia por emissão de pósitrons PET/CT com 18F-Fluordeoxiglicose (FDG)

7- Linfopenia

8- Alterações do parênquima pulmonar consistentes com sarcoidose, conforme determinado por pneumologistas ou radiologistas.

IV- Critério diagnóstico.

Sarcoidose ocular definitiva: diagnostico confirmação por biópsia e uveíte compatível.

Sarcoidose ocular presumida: diagnostico não confirmado por biópsia, mas adenopatia hilar bilateral presente + dois sinais intraoculares.

Sarcoidose provável: diagnóstico não confirmado por biopsia e ausência de adenopatia hilar bilateral, mas presença de três sinais intraoculares e de duas investigações sistêmicas (incluídas do item 2 a 8).

Diagnóstico Diferencial: tuberculose, sífilis, Vogt-Koyanagi-Harada, oftalmia simpática e Behçet.

\section{Tratamento:}

Uveíte anterior: corticoides tópicos (dexametasona $0,1 \%$ ou prednisolona $1 \%$ ) e cicloplégicos.(41)(43)

Nos casos em que não há melhora, deve-se escolher uma dentre as seguintes medicações: corticoide oral (prednisona $1 \mathrm{mg} / \mathrm{kg} / \mathrm{dia}$ ), injeção subtenoniana de triancinolona $1 \mathrm{~mL}(40 \mathrm{mg})$, injeção intravítrea de triancinolona $4 \mathrm{mg} / 0,1 \mathrm{~mL}$ e droga de liberação lenta (dexametasona 0,7mg).(39)(41)

Considerar o uso de imunossupressores quando houver alterações sistêmicas em conjunto com a uveíte.

Acometimento de segmento posterior (uveíte intermediária, uveíte posterior e panuveíte):

Casos unilaterais: considerar corticoide oral (prednisona $1 \mathrm{mg} / \mathrm{kg} / \mathrm{dia}$ ) ou injeção subtenoniana de triancinolona $1 \mathrm{~mL}(40 \mathrm{mg})$ ou injeção intravítrea de triancinolona $4 \mathrm{mg} / 0,1 \mathrm{~mL}$ ou droga de liberação lenta (dexametasona $0,7 \mathrm{mg}) \cdot(39)(41)$

Casos bilaterais: medicação sistêmica (corticoide oral ou endovenoso.(39)(43) Corticoide oral: prednisona $1 \mathrm{mg} / \mathrm{kg} / \mathrm{dia}$. (39) 
Corticoide EV: pulsoterapia principalmente nos casos de edema macular grave, vasculite retiniana e acometimento de nervo óptico.

Metilprednisolona $1000 \mathrm{mg}$ em adultos e $30 \mathrm{mg} / \mathrm{kg}$ em crianças em um período de 3 dias.

\section{Imunossupressores}

Metotrexato: Comprimido 2,5mg. Dose 10-15mg por semana VO ou SC.

Dose máxima 20-25mg. (11)

Associar ácido fólico $5 \mathrm{mg}$ no dia seguinte ao uso do MTX.

Considerar a troca do uso oral pelo uso subcutâneo quando não houver boa resposta.

Azatioprina: comprimido $50 \mathrm{mg}$ via oral. Dose $2,5 \mathrm{mg} / \mathrm{kg} / \mathrm{dia}$. Dose máxima $3 \mathrm{mg} / \mathrm{kg} / \mathrm{dia}$.(11)(43)

Ciclosporina A: cápsulas de $10 \mathrm{mg}, 25 \mathrm{mg}, 50 \mathrm{mg}, 100 \mathrm{mg}$ e solução oral 100 $\mathrm{mg} / \mathrm{mL}$.(11)(43) Dose: $2-5 \mathrm{mg} / \mathrm{kg} / \mathrm{dia}$ dividido em duas tomadas.(44)Dose máxima de $7 \mathrm{mg} / \mathrm{kg} / \mathrm{dia}$.(11)

\section{Imunobiológicos:}

Infliximab: dose 5-10mg/kg por infusão venosa na semana 0, 2, 6 .

Dose de manutenção a cada 4-8 semanas.(43)(45)

Adalimumab: $40 \mathrm{mg}$ a cada $1-2$ semanas. Via subcutânea.(43)(45)

Outros: (45)(46)(47)

Golimumab: $50 \mathrm{mg} 1 \mathrm{x}$ ao mês. SC

Certolizumab: $400 \mathrm{mg}$ na semana $0,2,4$. Após $200 \mathrm{mg}$ a cada 15 dias ou $400 \mathrm{mg}$ a cada mês. SC

Tocilizumab: 4-12 $\mathrm{mg} / \mathrm{kg}$ a cada 2-4 semanas. IV

Obs: sempre buscar o melhor canal de comunicação possível entre 0 oftalmologista e o reumatologista para acompanhamento da atividade ocular e sistêmica, e escolha do tratamento. 


\subsubsection{Resumo Esclerite idiopática}

É uma inflamação da esclera que pode acometer a parte anterior e/ou posterior do olho, sendo classificada em difusa, nodular e necrosante.(48)

Diagnóstico: de exclusão.

Grau de inflamação da esclerite anterior: (49)(50)

0 : sem inflamação escleral com branqueamento completo dos vasos.

0,5+: traço de inflamação com vasos episclerais profundos minimamente dilatados.

1+: inflamação escleral leve com dilatação difusa leve dos vasos episclerais profundos.

2+: inflamação escleral moderada com vasos episclerais tortuosos e profundos ingurgitados.

$3+$ : inflamação escleral grave com vermelhidão difusa significativa da esclera \pm obscurecimento dos vasos episclerais profundos com edema e eritema.

4+: esclerite necrosante com ou sem exposição uveal.

Investigação: o diagnóstico deve ser feito por exclusão, investigando-se inicialmente as doenças autoimunes, infecciosas, síndromes mascaradas e história de trauma ocular. As principais doenças são: artrite reumatoide, granulomatose com poliangeíte, policondrite recidivante, lúpus eritematoso, sarcoidose, poliarterite nodosa, herpes, sífilis, tuberculose e infecções fúngicas. Solicitar ultrassonografia ocular para os quadros de esclerite posterior.(48)(51)

\section{Tratamento}

AINES: pode ser usado na esclerite anterior com ou sem doença sistêmica. (52)(53)(54)

Indometacina: $75 \mathrm{mg}, \mathrm{VO}, 2 \mathrm{x}$ ao dia. Crianças: $2-4 \mathrm{mg} / \mathrm{kg} / \mathrm{dia}$ ou

Ibuprofeno: 200mg, VO, 2-3x ao dia. Crianças: $10 \mathrm{mg} / \mathrm{kg}$ dia de $6 / 6 \mathrm{hs}$.

Obs: considerar o uso de injeção subtenoniana de triancinolona $1 \mathrm{~mL}(40 \mathrm{mg})$ em casos unilaterais, sem risco de perfuração, e nos casos contraindicados ao uso de AINES (doença renal grave ou história de úlcera gástrica). (55)

Corticoide oral: nos casos de esclerite anterior, sem associação a doenças sistêmicas, que não responde aos AINES, nos de esclerite anterior associada à doença sistêmica e na esclerite posterior.(51)

Prednisona: $1 \mathrm{mg} / \mathrm{kg}$ ao dia. Via oral (VO) (provisório até entrada de DMD)(52) 
Corticoide endovenoso: nos casos de esclerite necrosante ou com risco de perfuração.

Metilprednisolona: 1000mg por 3 dias (pulsoterapia).

Ciclofosfamida: dose de 2-3mg/kg/dia. Nos casos de esclerite necrosante ou risco de perfuração. (muito usado nas vasculites sistêmicas).

\section{Imunossupressores}

Metotrexato (MTX): comprimido 2,5mg. Dose $10-15 \mathrm{mg}$ por semana VO. Dose máxima 20-25mg. Acido fólico $5 \mathrm{mg}$ no dia seguinte ao MTX.

Considerar a troca do uso oral pelo uso subcutâneo quando não houver boa resposta.(11)(52)(56)

Azatioprina: comprimido $50 \mathrm{mg}$ via oral. Dose $2,5 \mathrm{mg} / \mathrm{kg} / \mathrm{dia}$. Dose máxima $3 \mathrm{mg} / \mathrm{kg} / \mathrm{dia}$.(11)(52)

Micofenolato mofetil: Comprimido: 500mg. Suspensão: $200 \mathrm{mg} / \mathrm{ml}$ VO. (52)(56)(57)

Dose inicial $500 \mathrm{mg} 2 \mathrm{x}$ ao dia. Dose máxima: $1,5 \mathrm{~g} 2 \mathrm{x} / \mathrm{dia}$. Dose recomendada: $1 \mathrm{~g} 2 \mathrm{x} / \mathrm{dia}$.

Caso não ocorra melhora, deve-se avaliar a troca por um biólogico. Imunobiológicos:

Adalimumab: $40 \mathrm{mg}$ a cada $1-2$ semanas. Subcutânea (SC).(58)

Infliximab: dose $5-10 \mathrm{mg} / \mathrm{kg}$ por infusão venosa na semana $0,2,6$. Dose de manutenção a cada 4-8 semanas. (58)(59)

Rituximab: $1000 \mathrm{mg}$ aplicados no dia 0 e 14. Após, a cada 6 meses. (45)(51)(54)

Outros: Tocilizumab, golimumab e certolizumab. (45)(47)

Obs: sempre buscar o melhor canal de comunicação possível entre o oftalmologista e o reumatologista para acompanhamento da atividade ocular e sistêmica, e escolha do tratamento. 


\subsubsection{Resumo Pars planite}

É uma uveíte intermediária de causa desconhecida que não possui associação com outras doenças.(60)

Etiologia: desconhecida.(60)

Diagnóstico: de exclusão.(60)

Diagnóstico ocular: baixa de visão, floaters, fotofobia e vitreíte. Esta última é a principal característica. Podem ser encontrados snowballs e snowbanks. (60) Investigação: por ser um diagnóstico de exclusão, devem-se investigar as seguintes doenças: tuberculose, sifilis, sarcoidose, toxoplasmose e esclerose multipla.(60)

Diagnóstico diferencial: sarcoidose, sífilis, tuberculose, esclerose múltipla, toxoplasmose, Behçet, AlJ e HLA-B27.

\section{Tratamento:}

Unilateral: considerar o uso de corticoide oral (prednisona $1 \mathrm{mg} / \mathrm{kg} / \mathrm{dia}$ ) ou de injeção subtenoniana de triancinolona $1 \mathrm{~mL}(40 \mathrm{mg})$ ou de injeção intravítrea de triancinolona $4 \mathrm{mg} / 0,1 \mathrm{~mL}$ ou de droga de liberação lenta (dexametasona $0,7 \mathrm{mg}) \cdot(60)$

Optando-se pelas injeções, caso não ocorra melhora com a primeira aplicação, esta pode ser repetida em até $3 x$.

Bilateral: medicação sistêmica (corticoide oral ou endovenoso).

Corticoide oral: prednisona $1 \mathrm{mg} / \mathrm{kg} / \mathrm{dia}$. (60)

Corticoide EV: pulsoterapia nos casos que precisam de resposta rápida.

Metilprednisolona $1000 \mathrm{mg}$ em adultos e $30 \mathrm{mg} / \mathrm{kg}$ em crianças em um período de 3 dias.(60)

\section{Imunossupressores:}

Metotrexato: comprimido 2,5mg. Dose $10-15 \mathrm{mg}$ por semana VO. Dose máxima 20-25mg. Acido fólico $5 \mathrm{mg}$ no dia seguinte ao MTX.

Considerar a troca do uso oral pelo uso subcutâneo quando não houver boa resposta.(11)(60)(61)(62)

Azatioprina: comprimido $50 \mathrm{mg}$ via oral. Dose $2,5 \mathrm{mg} / \mathrm{kg} / \mathrm{dia}$. Dose máxima $3 \mathrm{mg} / \mathrm{kg} / \mathrm{dia} .(11)(60)(61)(62)$

Ciclosporina A: cápsulas de 10 mg, 25 mg, 50 mg, 100 mg e solução oral 100 $\mathrm{mg} / \mathrm{mL}$.

Dose: $2-5 \mathrm{mg} / \mathrm{kg} / \mathrm{dia}$ dividido em duas tomadas. 
Dose máxima de 7 mg/kg/dia.(11)(44)(60)(61)

Micofenolato de mofetil: comprimido: $500 \mathrm{mg}$. Suspensão: $200 \mathrm{mg} / \mathrm{ml} \mathrm{VO}$.

Dose inicial 500mg 2x ao dia. Dose recomendada: $1 \mathrm{~g} 2 \mathrm{x} / \mathrm{dia} .(56)(57)(60)(61)$

Imunobiológicos:

Adalimumab: $40 \mathrm{mg}$ a cada 1-2 semanas. Via subcutânea.(11)(60)

Infliximab: dose $5-10 \mathrm{mg} / \mathrm{kg}$ por infusão venosa na semana $0,2,6$. Dose de manutenção a cada 4-8 semanas.(60)(63)

Outros:(60)

Vitrectomia pars plana: hemorragia vítrea, descolamento retiniano, opacidade vítrea severa, membrana epirretiniana e tração vitreomacular.

Fotocoagulação e crioterapia: tratamento adjuvante nos casos de neovascularização periférica, tração retiniana e retinosquise.

Obs1: sempre buscar o melhor canal de comunicação possível entre o oftalmologista e o reumatologista para a escolha do tratamento. 


\subsubsection{Resumo Uveítes por HLA-B27/Espondiloartropatias}

As espondiloartropatias constituem um conjunto de doenças com características clínicas e laboratoriais em comum, sendo elas: espondilite anquilosante, artrite psoriásica, artrite reativa, enteroartropatias e as espondiloartropatias indiferenciadas.(64)

Etiologia: desconhecida. Sabe-se da associação com a presença do antígeno HLA-B27.

\section{Diagnóstico ocular:}

-Uveíte anterior unilateral ou bilateral, não granulomatosa, com presença de precipitados ceráticos finos. Casos severos podem apresentar hipópio. (65)(66) -Uveíte intermediaria/posterior: apesar de serem raras, estão presentes nas doenças inflamatórias intestinais.(66)

Investigação: HLA-B27, raio-x de coluna cervical, torácica, lombossacra e sacroilíacas.

Diagnóstico diferencial: herpes, AIJ, sífilis, sarcoidose, Behçet e tuberculose. Tratamento:

Uveite anterior: corticoides tópicos (dexametasona $0,1 \%$ ou prednisolona $1 \%$ ) e cicloplégicos.(67)(64) Não havendo melhora, avalia-se a possibilidade de uso de injeção subtenoniana de triancinolona $1 \mathrm{~mL}(40 \mathrm{mg})$ ou prednisona $1 \mathrm{mg} / \mathrm{kg} / \mathrm{dia}$.(68)(69)

\section{Acometimento de segmento posterior (casos raros)(67)(68)}

Unilateral: considerar corticoide oral (prednisona $1 \mathrm{mg} / \mathrm{kg} / \mathrm{dia}$ ) ou injeção subtenoniana de triancinolona $1 \mathrm{~mL}(40 \mathrm{mg})$ ou injeção intravítrea de triancinolona $4 \mathrm{mg} / 0,1 \mathrm{~mL}$ ou droga de liberação lenta (dexametasona 0,7mg).(67)(68)

Bilateral: prednisona $1 \mathrm{mg} / \mathrm{kg} / \mathrm{dia}$.

\section{Imunossupressores:}

Metotrexato (MTX): comprimido 2,5mg. Dose $10-15 \mathrm{mg}$ por semana VO. Dose máxima 20-25mg. Ácido fólico 5mg no dia seguinte ao MTX.(64)(65)(70)

Considerar a troca do uso oral pelo uso subcutâneo quando não houver boa resposta.

O metotrexato teve uma melhor resposta ao edema macular comparado a sulfassalazina. 
Sulfassalazina: comprimido 500mg. Dose inicial: 500mg/dia. Dose recomendada: 2000mg/dia, 2x ao dia, VO. Associar ácido fólico 5 mg, 3 vezes/ semana. (64)(65)(70)

Azatioprina: comprimido $50 \mathrm{mg}$ via oral. Dose $2,5 \mathrm{mg} / \mathrm{kg} / \mathrm{dia}$. Dose máxima $3 \mathrm{mg} / \mathrm{kg} / \mathrm{dia} .(11)(65)$ Imunobiológicos:(69)

Adalimumab: $40 \mathrm{mg}$ a cada 1-2 semanas. Via subcutânea.(64)(68)(71)(72)

Infliximab: dose $5-10 \mathrm{mg} / \mathrm{kg}$ por infusão venosa na semana $0,2,6$. Dose de manutenção a cada 4-8 semanas.(64)(68)(71)(72)

Certolizumab: $400 \mathrm{mg}$ na semana $0,2,4$. Após, $200 \mathrm{mg}$ a cada 15 dias ou 400mg a cada mês. Subcutâneo.(45)(73)

Golimumab: 50mg 1x ao mês. Subcutâneo.(45)(74)

Obs: sempre buscar o melhor canal de comunicação possível entre 0 oftalmologista e o reumatologista para acompanhamento da atividade ocular e sistêmica, e escolha do tratamento. 


\subsubsection{Resumo Uveíte anterior idiopática}

É uma inflamação caracterizada pelo acometimento da íris ou da parte anterior do corpo ciliar.(5)

Diagnóstico: de exclusão.

Investigação: o diagnóstico deve ser feito por exclusão, investigando-se inicialmente as seguintes doenças: herpes, artrite idiopática juvenil (AIJ), ciclite heterocrômica de Fuch's, espondiloartropatias, tuberculose, sífilis e citomegalovírus.

Diagnóstico diferencial: AIJ, herpes, espondiloartropatias, tuberculose, sífilis e citomegalovírus.

\section{Tratamento:}

Corticoides tópicos: dexametasona $0,1 \%$ ou prednisolona $1 \%$, associados a cicloplégicos.(75)(76)

Não havendo melhora, avalia-se a possibilidade de uso de injeção subtenoniana de triancinolona $1 \mathrm{~mL}$ (40mg) ou prednisona $1 \mathrm{mg} / \mathrm{kg} / \mathrm{dia}$, $\mathrm{VO}$.

Corticoide oral: prednisona $1 \mathrm{mg} / \mathrm{kg} / \mathrm{dia}$. Via oral.(75)(77)

\section{Imunossupressores:}

Metotrexato (MTX): comprimido 2,5mg. Dose 10-15mg por semana, VO. Dose máxima 20-25mg. Ácido fólico 5mg no dia seguinte ao MTX.(76)(77)(78)

Considerar a troca do uso oral pelo uso subcutâneo quando não houver boa resposta.

O metotrexato teve uma melhor resposta ao edema macular que a sulfassalazina.

Sulfassalazina: comprimido 500mg. Dose inicial: $500 \mathrm{mg} / \mathrm{dia}$. Dose recomendada: 2000mg/dia, 2x ao dia, VO. Associar ácido fólico $5 \mathrm{mg}, 3$ vezes/ semana.(76)

Azatioprina: comprimido $50 \mathrm{mg}$ via oral. Dose $2,5 \mathrm{mg} / \mathrm{kg} / \mathrm{dia}$. Dose máxima $3 \mathrm{mg} / \mathrm{kg} / \mathrm{dia} .(11)(75)$

\section{Imunobiológicos:}

Adalimumab: $40 \mathrm{mg}$ a cada 1-2 semanas. Via subcutânea.(75)(77)(79)

Infliximab: dose $5-10 \mathrm{mg} / \mathrm{kg}$ por infusão venosa na semana $0,2,6$. Dose de manutenção a cada 4-8 semanas.(79) 
Obs: sempre buscar o melhor canal de comunicação possível entre o oftalmologista e o reumatologista para acompanhamento da atividade ocular e sistêmica, e escolha do tratamento. 


\subsubsection{Resumo Vogt-Koyanagi-Harada / Oftalmia Simpática}

Doença autoimune com acometimento ocular bilateral caracterizada pelas seguintes fases: prodrômica, uveítica, convalescência e crônica.(80)(81)(82)

\section{Diagnóstico}

Completa: acometimento neurológico, ocular, auditivo e cutâneo.

Incompleta: acometimento ocular associado a alterações neurológicas/auditivas ou associado ao acometimento cutâneo.

Provável: apenas o acometimento ocular.

Critérios: ausência de história de trauma ocular penetrante ou cirurgia precedendo o início da uveíte; ausência de história clínica ou laboratorial de outra doença ocular; envolvimento ocular bilateral(a) ou (b); presença de achados neurológicos/ auditivos (que já podem ter desaparecido no momento da apresentação clínica) ou; achados dermatológicos, sendo que estes nunca devem preceder a doença ocular ou as manifestações neurológicas. (83)

a- Manifestações precoces

1- Coroidite difusa, área focal de fluido subretiniano e descolamento seroso de retina.

2- Se houver achados equívocos no fundo de olho, devem estar presente:

a) Áreas focais de atrasos na perfusão de coroide, áreas multifocais de vazamento pontual, grandes áreas placóides de hiperfluorescência, pooling com fluido subretiniano e staining de nervo óptico.

b) Espessamento de coroide difuso, sem evidencia de esclerite posterior pela ultrassonografia.

b- Manifestações tardias

1- História sugestiva de doença prévia com base nos achados a seguir

2- Despigmentação ocular: fundo do olho em pôr-do-sol ou sinal de Sugiura

3- Outros sinais como cicatrizes coriorretinianas numulares despigmentadas, alterações de EPR ou uveíte anterior crônica recorrente

Investigação: ultrassom ocular, tomografia de coerência óptica, angiografia com fluoresceína e indocianina verde e punção lombar.(80)(82)

Diagnóstico Diferencial: oftalmia simpática, tuberculose, sífilis, sarcoidose, lúpus, infecção fúngica e linfoma intraocular.

\section{Tratamento}

\section{Fase aguda/uveítica:}


Corticoide oral: prednisona $1 \mathrm{mg} / \mathrm{kg} / \mathrm{dia}$. VO.(84)(85)

Corticoide EV: pulsoterapia nos casos graves.(84)

Metilprednisolona: $1000 \mathrm{mg}$ por 3 dias.(11)

Imunossupressor: deve ser iniciado junto ao corticoide, por ser uma doença sistêmica.

\section{Imunossupressores:}

Azatioprina: comprimido $50 \mathrm{mg}$ via oral. Dose $2,5 \mathrm{mg} / \mathrm{kg} / \mathrm{dia}$. Dose máxima $3 \mathrm{mg} / \mathrm{kg} / \mathrm{dia} .(11)(85)(86)(87)$

Ciclosporina A: cápsulas de $10 \mathrm{mg}, 25 \mathrm{mg}, 50 \mathrm{mg}, 100 \mathrm{mg}$ e solução oral 100 $\mathrm{mg} / \mathrm{mL}$. Dose: $2-5 \mathrm{mg} / \mathrm{kg} /$ dia dividido em duas tomadas. Dose máxima de 7 $\mathrm{mg} / \mathrm{kg} / \mathrm{dia} .(11)(85)(86)(87)$

Metotrexato: comprimido 2,5mg. Dose $10-15 \mathrm{mg}$ por semana VO. Dose máxima 20-25mg. Acido fólico $5 \mathrm{mg}$ no dia seguinte ao MTX.(11)

Considerar a troca do uso oral pelo uso subcutâneo quando não houver boa resposta.(86)

\section{Imunobiológicos:}

Adalimumab: $40 \mathrm{mg}$ a cada 1-2 semanas. Via subcutânea.(45)(85)(86)(88)

Infliximab: dose $5-10 \mathrm{mg} / \mathrm{kg}$ por infusão venosa na semana $0,2,6$. Dose de manutenção a cada 4-8 semanas.(45)(47)(85)(86)

Rituximab: apresentação: $100 \mathrm{mg} / 10 \mathrm{~mL}$ e $500 \mathrm{mg} / 50 \mathrm{~mL}$. Dose: $1000 \mathrm{mg}$ nos dias 0 e 14. Após 500-1000mg a cada 6 meses. Intravenoso.(84)

\section{Fase crônica recorrente:}

Uveíte anterior: corticoides tópicos (dexametasona $0,1 \%$ ou prednisolona $1 \%$ ) e cicloplégicos.

Em casos refratários e com edema macular persistente, deve-se avaliar a possibilidade de injeção subtenoniana de triancinolona $1 \mathrm{~mL}(40 \mathrm{mg})$ ou injeção intravítrea de triancinolona $4 \mathrm{mg} / 0,1 \mathrm{~mL}$ ou droga de liberação lenta (dexametasona $0,7 \mathrm{mg}$ ) ou prednisona $1 \mathrm{mg} / \mathrm{kg} /$ dia.(85)(86)

Obs: a diferença entre VKH e oftalmia simpática é que na ultima tem que ter a presença de trauma ou cirurgia previa.

Obs1: sempre buscar o melhor canal de comunicação possível entre o oftalmologista e o reumatologista para acompanhamento da atividade ocular e sistêmica, e escolha do tratamento. 


\subsection{Resumo das drogas mais usadas no tratamento das uveítes não infecciosas}

Ao longo dos fluxogramas, é possível perceber que várias medicações foram citadas, como: metotrexato, azatioprina, ciclosporina, micofenolato tacrolimus, adalimumab, infliximab, rituximab, golimumab, tocilizumab e certolizumab. Porém, várias delas não foram selecionadas para a elaboração dos resumos.

Dessa maneira, as drogas separadas para a composição dos resumos foram: metotrexato, azatioprina e adalimumab. A sua escolha ocorreu por representarem as medicações mais citadas nos artigos como sendo as de primeira linha dos imunossupressores, além de serem as mais utilizadas na prática clínica dos ambulatórios do RAU e IURE.

Outro fator que pode ser considerado para a sua escolha deve-se ao fácil acesso ao metotrexato e a azatioprina, além de seu baixo custo em relação às outras medicações.

Sendo assim, criou-se um modelo para o metotrexato que serviu de referência para as outras duas medicações. Consta no mesmo os seguintes aspectos: apresentação, administração, mecanismo de ação da droga, a via principal de eliminação, posologia, dose máxima necessária para chegar-se ao seu efeito esperado, tempo necessário para a droga apresentar o efeito esperado e o seu efeito máximo; os exames a serem solicitados antes do seu inicio; monitoramento e, por fim, os principais efeitos colaterais.

Logo, para a criação do resumo do metotrexato foram analisados quatro artigos. O principal artigo foi o guidelines sobre as drogas imunossupressoras, (23) o qual serviu de base tanto para o metotrexato como para azatioprina, micofenolato e ciclosporina.

Em relação à azatioprina, também foram avaliados 4 artigos. Já em relação ao adalimumab, foram verificados 6 artigos.

É importante esclarecer que foi elaborado um resumo geral das medicações citadas nos fluxogramas, pois as condutas terapêuticas de cada doença estavam se repetindo ao longo dos resumos, prejudicando assim a objetividade do trabalho.

Logo, esses resumos irão ajudar na prescrição das medicações, bem como no monitoramento dos pacientes ao longo das consultas, evitando assim possíveis efeitos colaterais e iatrogênias.

Seguem abaixo os resumos. 


\subsubsection{Resumo Metotrexato}

Apresentação: comprimido de 2,5mg. Solução injetável de $50 \mathrm{mg}$. Embalagem com 1 frasco-ampola de $2 \mathrm{~mL}$. Solução injetável de $500 \mathrm{mg}$. Embalagem com 1 frasco-ampola de $20 \mathrm{~mL}$.(57)

Administração: oral (7,5- 25mg por semana), intramuscular (7,5- 50mg por semana) e intravítrea (dose de 400 microgramas/0.1 mL).(57)(89)

Mecanismo: análogo do acido fólico. Inibe a dihidrofolato redutase (enzima responsável pela conversão dihidrofolato em tetrahidrofolato), assim inibindo a replicação do DNA.(57)

Eliminação: renal. Meia vida de 3-10 horas, porém em altas doses pode ser prolongada para 8-15 horas.

Indicações: artrite idiopática juvenil, espondilite anquilosante, artrite reativa, artrite psoriásica, doença inflamatória intestinal, sarcoidose e vasculite. (57)

Posologia: criança: $15 \mathrm{mg} / \mathrm{m}^{2}$ por semana. Calcular superfície corpórea. Adulto: $15 \mathrm{mg} /$ semana.(20)(89)

Iniciar: dose de $7,5 \mathrm{mg}$ e aumentar $2,5 \mathrm{mg}$ por semana até atingir $15 \mathrm{mg} / \mathrm{semanal}$.(89)

Prescrever: ácido fólico $5 \mathrm{mg}$ no dia seguinte.(20)

Dose máxima: 25mg/semana (VO), 50mg/semana (IM), 200mg/semana (IV).(20)

Efeito da medicação: inicio com 2 semanas.

Efeito máximo da droga: 6-8 semanas.(90)

Exames solicitados antes da prescrição: hemograma completo, TGO, TGP e sorologias para hepatite $B$ e $C, \beta-H C G$ em mulheres em idade fértil.

Monitoramento: hemograma completo, TGO, TGP a cada 3 meses.(20)

Efeitos colaterais: hepatoxicidade, citopenias, sintomas gastrointestinais (náuseas, anorexia, estomatite), perda de cabelo, pneumonia intersticial e cirrose.(20)

Contraindicação: gravidez e ingesta concomitante de bebida alcoólica.

Observações:

Diminuir a dose quando as enzimas hepáticas aumentarem em duas vezes o limite normal e suspender quando aumentarem em três vezes o limite normal de referência.(20) 
Manter por pelo menos 12 meses após inativação da doença, e nos casos de pior prognóstico manter por mais de 24 meses. (20) 


\subsubsection{Resumo Azatioprina}

Apresentação: comprimido de 50mg.(57)

Administração: via oral.

Mecanismo: análogo de nucleotídeos das purinas. Interfere na síntese de RNA e DNA. Diminui o número de linfócitos periféricos $\mathrm{T}$ e $\mathrm{B}$, diminui a reativação de linfócitos, interleucina-2 e produção de IgM.(57)(89)

Eliminação: renal.(91)

Indicações: artrite idiopática juvenil, Vogt-Koyanagi-Harada, Behçet, sarcoidose, pars planite e lúpus.(57)

Posologia: pode ser uma $1 \mathrm{x}$ ao dia ou dividido em $2 \mathrm{x}$ ao dia.

Iniciar: $75-100 \mathrm{mg} / \mathrm{dia} \quad(1 \mathrm{mg} / \mathrm{kg} / \mathrm{dia})$ e aumentar para $200-250 \mathrm{mg} / \mathrm{dia}$ (3mg/kg/dia).(57)(89)(92)

Dose máxima: 3mg/kg/dia.(89)

Efeito da medicação: inicio com 4 semanas.

Efeito máximo da droga: 1-3 meses.

Exames solicitados antes da prescrição: hemograma completo, TGO, TGP, ureia e creatinina, sorologias para hepatite B e C, HIV, PPD, sorologia para varicela zoster.(91)

Monitoramento: hemograma completo a cada 4-6 semanas, TGO, TGP, ureia e creatinina a cada 3-6 semanas.(57)

Efeitos colaterais: hepatoxicidade, citopenias, sintomas gastrointestinais (náuseas, anorexia, estomatite), aumenta risco de linfoma $\mathrm{NH}$ e pancreatite. (57)(91)

Contraindicação: insuficiência hepática.(91)

Observações:

Caso ocorra toxicidade hepática e as enzimas aumentarem cerca de um e meio do limite de referência, deve-se diminuir em $25-50 \mathrm{mg} /$ dia e solicitar enzimas a cada 2 semanas. Caso as enzimas elevem mais de cinco vezes 0 limite de referência a azatioprina deve ser descontinuada.

Manter por pelo menos 12 meses após inativação da doença, e nos casos de pior prognóstico manter por mais de 24 meses.

Não realizar aplicação de vacinas de vírus vivo enquanto fizer uso de azatioprina. 
Interações: com alopurinol (reduz a dose em $1 / 4$ da azatioprina), captopril e aminosalicilatos aumentam o risco de leucopenia. 


\subsubsection{Resumo Adalimumab}

Apresentação: $40 \mathrm{mg}$ em seringa com $0,8 \mathrm{~mL}$.

Administração: subcutânea.

Mecanismo: é um anticorpo monoclonal lg 1 humanizado anti-TNF- $\alpha$. TNF- $\alpha$ é uma citocina pró-inflamatória produzida por macrófagos e células T. (20)

Eliminação: renal. Pico de concentração sérica com cinco dias.(93)

Indicações: uveíte intermediária, posterior e panuveíte.(93)

Posologia: crianças: $24 \mathrm{mg} / \mathrm{m}^{2}$ por semana. Adultos: $40 \mathrm{mg}$ por semana.

Iniciar: 20-40mg a cada 2 semanas.(89)(92)

Dose máxima: crianças 2-3 anos (20mg/semana), crianças 4-12 anos (40mg/semana), crianças > 13 anos (40mg/semana). $(20)$

Efeito da medicação: inicio com 4 semanas.

Efeito máximo da droga: 1-2 meses.

Exames solicitados antes da prescrição: hemograma completo, TGO, TGP, sorologia para hepatite B e teste tuberculínico.(20)(89)(90)

Monitoramento: hemograma completo a cada 3 meses, TGO, TGP a cada 3-6 semanas e teste tuberculínico anual.(20)

Efeitos colaterais: hepatotoxicidade, sepse, anafilaxia, lúpus induzido por droga e neoplasias.(92)

Contraindicação: crianças menores de 2 anos.

Observações:

Manter por pelo menos 12 meses após inativação da doença, e nos casos de pior prognóstico manter por mais de 24 meses.(20)

Aumenta o risco de ativação de infecção latente na tuberculose e hepatite.

Não realizar aplicação de vacinas de vírus vivo enquanto fizer uso de adalimumab. 


\subsubsection{Resumo Geral das Medicações}

Antes de iniciar corticoide em dose imunossupressora: excluir principais doenças infecciosas (sífilis e tuberculose).

Certificar se Derivado Proteico Purificado (PPD) foi negativo e se não houve alterações no raio $X$ de tórax. Em casos graves, não é preciso aguardar 0 resultado dos exames. Deve-se iniciar o corticoide e solicitar o Interferon Gama Release Assay (IGRA) se disponível em cada serviço.

Corticoide oral: prednisona $1 \mathrm{mg} / \mathrm{kg}$ dia.(57)

Associar cálcio e Vitamina D (500-1000mg + 400Ul 2x ao dia) se prednisona > $5 \mathrm{mg}$ por 3 meses. (33)(34)

Aferição da pressão arterial. Dieta hipossódica.

Corticoide endovenoso: pulsoterapia com 1000mg de metilprednisolona + $500 \mathrm{~mL}$ de soro fisiológico $0,9 \%$ por 3 dias. Fazer uso de albendazol $400 \mathrm{mg}$ por 5 dias.(11)

Solicitar antes de iniciar a pulsoterapia: hemograma, sódio, potássio, glicemia (antes e após). Aferir pressão a cada 30 minutos durante infusão. Se pressão arterial sistólica $>180 \mathrm{mmHg}$ e/ ou diastólica $>120 \mathrm{mmHg}$, suspender infusão.

\section{Imunossupressores:}

É preciso considerar seu uso em três situações. Primeiramente, quando o corticoide não tem uma resposta adequada. Segundo, quando o paciente não consegue reduzir a dose de corticoide e, por último, nos pacientes com contraindicação ao seu uso.

Metotrexato: comprimido de 2,5mg. Solução injetável de $50 \mathrm{mg}$ e embalagem com 1 frasco-ampola de $2 \mathrm{~mL}$. Solução injetável de $500 \mathrm{mg}$ e embalagem com 1 frasco-ampola de $20 \mathrm{~mL}$. Dose de $10-15 \mathrm{mg} / \mathrm{m}^{2}$ por semana via oral ou subcutânea.

Associar ácido fólico 5mg no dia seguinte ao uso do MTX.(11)(57)

Solicitar antes do início da medicação ou checar se o paciente já possui: albumina, gonadotrofina coriônica humana ( $\beta-\mathrm{HCG}$ ), hemograma completo, transaminase glutâmico-oxalacética (TGO) e transaminase glutâmico-pirúvica (TGP), sorologias para hepatite B (hepatitis B surface antigen- HBsAg e hepatitis B core antigen antibody- anti-HBc) e hepatite $C$ (hepatitis $C$ virus antibody-anti-HCV).(94) 
Monitoramento: hemograma completo, TGO e TGP no $1^{\circ}$ mês. Repetir a cada 3 meses. A cada 6 meses: albumina. Caso aumente $3 x$ VR suspender medicação

Considerar a troca do uso oral pelo uso subcutâneo quando não houver boa resposta.

Azatioprina: comprimido $50 \mathrm{mg}$ via oral. Dose $2,5 \mathrm{mg} / \mathrm{kg} / \mathrm{dia}$. Dose máxima $3 \mathrm{mg} / \mathrm{kg} /$ dia.(11)(57)

Solicitar antes do início da medicação ou checar se o paciente já possui: hemograma completo, TGO, TGP, ureia, creatinina, hepatite B (HBsAg e anti$\mathrm{HBc}$ ), hepatite $\mathrm{C}$, human immunodeficiency virus (HIV) e varicela zoster.

Certificar se PPD foi negativo e se não houve alterações no raio $X$ de tórax.

Monitoramento: solicitar hemograma completo, TGO, TGP, uréia e creatinina na 4 semana e após a cada 3 meses.

Ciclosporina A: cápsulas de $10 \mathrm{mg}, 25 \mathrm{mg}, 50 \mathrm{mg}, 100 \mathrm{mg}$ e solução oral 100 $\mathrm{mg} / \mathrm{mL}$. Dose: $2-5 \mathrm{mg} / \mathrm{kg} / \mathrm{dia}$ dividido em duas tomadas. Dose máxima de 7 $\mathrm{mg} / \mathrm{kg} / \mathrm{dia} .(11)(57)$

Solicitar antes do inicio da medicação ou checar se o paciente já possui: ureia, creatinina e medida da pressão arterial.(11)

Monitoramento: medida da pressão arterial nas primeiras 2 semanas por 3 meses e após a cada mês. A cada 3 meses: sódio, potássio, acido úrico, colesterol total, high density lipoprotein (HDL), triglicerídeos e TGO/TGP. Dosar ciclosporina a cada 3-6 meses. Avaliar ciclosporinemia.

Micofenolato de mofetil: comprimido: $500 \mathrm{mg}$. Suspensão: $200 \mathrm{mg} / \mathrm{ml} \mathrm{VO}$.

Dose inicial $500 \mathrm{mg} 2 \mathrm{x}$ ao dia. Dose máxima: $1,5 \mathrm{~g} 2 \mathrm{x} / \mathrm{dia}$.

Dose recomendada: $1 \mathrm{~g} 2 \mathrm{x} / \mathrm{dia}$.(56)(57)

Solicitar antes do inicio da medicação ou checar se o paciente já possui: $\beta$ HCG (mulheres em idade fértil), hemograma, TGO, TGP, hepatite B (HBsAg e anti-HBc), hepatite C (Anti-HCV).

Monitoramento: hemograma a cada semana por 1 mês, após a cada 2 semanas por dois meses, após mensal. TGO/TGP a cada 3 meses.

Sulfassalazina: comprimido $500 \mathrm{mg}$. Dose inicial: $500 \mathrm{mg} / \mathrm{dia}$.

Dose recomendada: $2000 \mathrm{mg} / \mathrm{dia}$, $2 x$ ao dia, VO.

Associar ácido fólico $5 \mathrm{mg}, 3$ vezes/ semana.(76) 
Solicitar antes do inicio da medicação ou checar se o paciente já possui: hemograma, creatinina, TGO, TGP, exame qualitativo de urina.

Monitoramento: hemograma, creatinina e exame qualitativo de urina a cada 4 meses. Se sintomas gastrointestinais reduzir dose em $50 \%$.

Contraindicação: porfiria, crianças $<2$ anos.

\section{Imunobiológicos:}

Adalimumab: $80 \mathrm{mg}$ no dia 0 . Após $40 \mathrm{mg}$ a cada $1-2$ semanas. Via subcutânea.(45)

Solicitar antes do inicio da medicação ou checar se o paciente já possui: hemograma completo, TGO, TGP, ureia e creatinina, sorologia para hepatite $B$ e C, HIV e varicela zoster. Certificar se PPD foi negativo e se não houve alterações no raio $X$ de tórax.

Monitoramento: hemograma completo, TGO e TGP a cada 3 meses.

Infliximab: dose $5-10 \mathrm{mg} / \mathrm{kg}$ por infusão venosa na semana $0,2,6$. Dose de manutenção a cada 4-8 semanas.(45)

Solicitar antes do inicio da medicação ou checar se o paciente já possui: hemograma completo, TGO, TGP, ureia e creatinina, sorologia para hepatite $B$ e C, HIV e varicela zoster. Certificar se PPD foi negativo e se não houve alterações no raio $X$ de tórax.

Monitoramento: hemograma completo, TGO e TGP a cada 3 meses.

Outros:

Rituximab: apresentação: $100 \mathrm{mg} / 10 \mathrm{~mL}$ e $500 \mathrm{mg} / 50 \mathrm{~mL}$. Dose: $1000 \mathrm{mg}$ nos dias 0 e 14. Após 500-1000mg a cada 6 meses. Intravenoso.(45)

Tocilizumab: $4-12 \mathrm{mg} / \mathrm{kg}$ a cada 2-4 semanas. Intravenoso.(45)

Golimumab: 50mg 1x ao mês. Subcutâneo.(45)

Certolizumab: $400 \mathrm{mg}$ na semana $0,2,4$. Após $200 \mathrm{mg}$ a cada 15 dias ou $400 \mathrm{mg}$ a cada mês. Subcutâneo.(45)

Obs: É importante lembra que até o presente estudo o único que foi liberado pelo FDA para uso em uveíte não infecciosas sendo elas intermediária, posterior e panuveite foi o adalimumb.(45) 


\section{Discussão}

Nas últimas décadas, houve avanços significativos nos métodos disponíveis para avaliação diagnóstica e nas opções terapêuticas para tratamento das uveítes não infecciosas. Desse modo, a avaliação objetiva destes pacientes se torna difícil na prática clínica, tendo em vista as várias abordagens disponíveis, algumas das quais sem evidência científica comprovada que justifique a sua utilização.

Diante disso, é esperada e necessária uma reformulação periódica dos fluxogramas, para que se tornem mais adequados à realidade, garantindo a sua utilidade e eficiência.

Como já foi dito, na grande maioria dos casos de uveítes não há um consenso quanto a conduta a ser adotada, razão pela qual procurou-se criar um protocolo de condutas com fundamento na prática diária, na opinião de especialistas e no estudo dos artigos triados neste trabalho. Nesse contexto, muitas vezes opta-se por determinada medicação não por sua comprovada eficácia científica, mas por sua disponibilidade na rede pública, além da experiência prática da equipe com a sua utilização. Dessa forma, a implementação destes protocolos no serviço traz inúmeros benefícios, viabilizando a padronização do atendimento e a sistematização do diagnóstico e do tratamento, tornando o atendimento mais prático e objetivo.

Além da falta de consensos, outra dificuldade encontrada relaciona-se ao grande número de artigos triados, exigindo-se mais tempo para a análise de seus dados.

Vale esclarecer que o fluxograma constitui apenas um resumo, servindo como um guia de orientação para o profissional médico, que deverá analisar as particularidades de cada paciente.

Além disso, a atuação em conjunto da reumatologia e da oftalmologia é importante para possibilitar uma avaliação mais completa do paciente, reduzindo as complicações e proporcionando sua melhor assistência.

Face ao exposto, conclui-se que este estudo procurou trazer orientações de fácil entendimento e aplicação para condução ambulatorial dos pacientes com suspeita de uveíte não infecciosa, otimizando o diagnóstico, tratamento e seguimento desta condição. 


\section{Conclusão}

Através da criação dos fluxogramas, buscou-se padronizar as condutas a serem adotadas nos ambulatórios RAU e IURE, de modo a auxiliar os oftalmologistas e os reumatologistas na tomada de decisões.

Contudo, é importante registrar que não se pretende indicar as condutas descritas nos fluxogramas de forma absoluta, uma vez que cada paciente necessita de uma avaliação individualizada, a partir da qual será possível fazer o diagnóstico específico, com a posterior indicação do tratamento a ser prescrito.

Portanto, o objetivo primordial deste trabalho voltou-se a padronizar as condutas através dos protocolos com a finalidade de obter o diagnóstico em menor espaço de tempo bem como garantir maior eficiência do tratamento, o qual será conduzido pelos ambulatórios RAU e IURE.

Dessa forma, acredita-se que os protocolos de condutas poderão contribuir para o aperfeiçoamento do monitoramento e tratamento dos pacientes bem como nas atividades da residência médica, resultando assim em uma melhor assistência, na redução do tempo de tratamento e, por consequência, na redução dos custos financeiros da Instituição. 


\section{Referências Bibliográficas}

1-Selmi C. Diagnosis and classification of autoimmune uveitis. Autoimmun Rev. 2014 Apr-May;13(4-5):591-4. doi: 10.1016/j.autrev.2014.01.006. Epub 2014 Jan 12. Review.

2-Denniston AK, Holland GN, Kidess A, Nussenblatt RB, Okada AA, Rosenbaum JT, et al. Heterogeneity of primary outcome measures used in clinical trials of treatments for intermediate, posterior, and panuveitis. Orphanet J Rare Dis 2015;10:97.

3-Rosenbaum JT, et al. New observations and emerging ideas in diagnosis and management of non-infectious uveitis: A review. Semin Arthritis Rheum. 2019. PMID: 31301816 Review.

4-Rathinam SR, Namperumalsamy P. Global variation and pattern changes in epidemiology of uveitis. Indian J Ophthalmol. 2007 May-Jun;55(3):173-83. Review.

5-Jabs DA, Nussenblatt RB, Rosenbaum JT; Standardization of Uveitis Nomenclature (SUN) Working Group. Standardization of uveitis nomenclature for reporting clinical data. Results of the First International Workshop. Am J Ophthalmol. 2005 Sep;140(3):509-16. Review.

6-Tsirouki T, Dastiridou A, Symeonidis, Ourania Tounakaki O, Brazitikou I, Kalogeropoulos C, Androudi S. A focus on the epidemiology of uveitis. Ocular Immunology \& Inflammation, 2016; 00(00): 1-15.

7-Finamor LP, Finamor Jr F, Muccioli C. Corticoterapia e Uveítes. Arquivo Brasileiro de Oftalmologia, 2002;65:483-6.

8-American Academy Of Ophthalmology. Guidelines. Disponível em: <https://www.aao.org/guidelines-browse?subspecialty=uveitis>. Acesso em: 15 de jun. de 2019. 
9-Conselho Brasileiro de Oftalmologia. Disponível em: < https://www.cbo.net.br/novo/classe-medica/>. Acesso em 15 de jun. de 2019.

10-Sociedade Brasileira de Uveítes. Disponível em: <http://www.uveitesbrasil.com.br/paginas/view/artigos.html>. Acesso em 15 de jun. de 2019.

11-Brasil. Ministério da Saúde. Secretaria de Atenção Especializada à Saúde. Portaria Conjunta no. 13, de 11 de setembro de 2019. Protocolos Clínicos e Diretrizes Terapêuticas Uveítes não Infecciosas. Diário Oficial da União. 16 set 2019; Seção 1. Disponível em: <http://saude.gov.br/protocolos-e-diretrizes>.

12-Cmaptools. Institute for Human \& Machine Cognition. Ocala. Florida. United States of America. Disponível em: < https://cmaptools.br.uptodown.com/windows>. Acesso em 14 de jul. de 2019.

13-American Academy of Ophthalmology. Basic and Clinical Science Course 2016-2017. Intraocular Inflammation and Uveitis. Chapter VI. Noninfectious Ocular Inflammatory Diseases, pg-119-18. San Francisco.

14-Gonzalez Fernandez D, Nascimento H, Nascimento C, Muccioli C, Belfort R Jr. Uveitis in São Paulo, Brazil: 1053 New Patients in 15 Months. Ocul Immunol Inflamm. 2017 Jun;25(3):382-387.

15-Pubmed. Disponível em: <https://www.ncbi.nlm.nih.gov/pubmed/)>.

16-Ouzzani M, Hammady H, Fedorowicz Z, Elmagarmid A. Rayyan-a web and mobile app for systematic reviews. Syst Rev. 2016 Dec 5;5(1):210.

17-Hatemi G, Christensen R, Bang D, Bodaghi B, Celik AF, Fortune F, Gaudric J, Gul A, Kötter I, Leccese P, Mahr A, Moots R, Ozguler Y, Richter J, Saadoun D, Salvarani C, Scuderi F, Sfikakis PP, Siva A, Stanford M, Tugal-Tutkun I, West R, Yurdakul S, Olivieri I, Yazici H. 2018 update of the EULAR 
recommendations for the management of Behçet. Ann Rheum Dis. 2018 Jun;77(6):808-818. doi: 10.1136/annrheumdis-2018-213225. Epub 2018 Apr 6.

18-Ferrara G, Mastrangelo G, Barone P, La Torre F, Martino S, Pappagallo G, Ravelli A, Taddio A, Zulian F, Cimaz R; Rheumatology Italian Study Group. Methotrexate in juvenile idiopathic arthritis: advice and recommendations from the MARAJIA expert consensus meeting. Pediatr Rheumatol Online J. 2018 Jul 11;16(1):46. doi: 10.1186/s12969-018-0255-8

19-Constantin T, Foeldvari I, Anton J, de Boer J, Czitrom-Guillaume S, Edelsten C, Gepstein R, Heiligenhaus A, Pilkington CA, Simonini G, Uziel Y, Vastert SJ, Wulffraat NM, Haasnoot AM, Walscheid K, Pálinkás A, Pattani R, Györgyi Z, Kozma R, Boom V, Ponyi A, Ravelli A, Ramanan AV. Consensus-based recommendations for the management of uveitis associated with juvenile idiopathic arthritis: the SHARE initiative.Ann Rheum Dis. 2018 Aug;77(8):1107-1117. doi: 10.1136/annrheumdis-2018-213131. Epub 2018 Mar 28.

20-Bou R, Adán A, Borrás F, Bravo B, Calvo I, De Inocencio J, Díaz J, Escudero J, Fonollosa A, de Vicuña CG, Hernández V, Merino R, Peralta J, Rúa MJ, Tejada P, Antón. Clinical management algorithm of uveitis associated with juvenile idiopathic arthritis: interdisciplinary panel consensus. J.Rheumatol Int. 2015 May;35(5):777-85. doi: 10.1007/s00296-015-3231-3. Epub 2015 Feb 6.

21-Cassidy J, Kivlin J, Lindsley C, Nocton J; Section on Rheumatology; Section on Ophthalmology. Ophtalmologic examinations in children with juvenile rheumatoid arthritis. Pediatrics. 2006 May; 117(5):1843-5. doi:10.1542/peds.2006-0421.

22-Ferrante P, Ramsey A, Bunce C, Lightman S (2004) Clinical trial to compare efficacy and side-effects of injection of posterior sub-Tenon triamcinolone versus orbital floor methylprednisolone in the management of posterior uveitis. Clin Exp Ophthalmol 32:563-568. 
23-Asproudis I, Katsanos A, Kozeis N, Tantou A, Konstas AG. Update on Treatment of Uveitis In Pacients with Juvenile Idiopathic Arthritis: A Review . Adv Ther. 2017 Dec;34(12):2558-2565. doi: 10.1007/s12325-017-0635-3. Epub 2017 Nov 16.PMID: 29143927 Review

24-Angeles-Han ST, Lo MS, Henderson LA, Lerman MA, Abramson L, Cooper AM, Parsa MF, Zemel LS, Ronis T, Beukelman T, Cox E, Sen HN, Holland GN, Brunner HI, Lasky A, Rabinovich CE; Juvenile Idiopathic Arthritis DiseaseSpecific and Uveitis Subcommittee of the Childhood Arthritis Rheumatology and Research Alliance. Childhood Arthritis and Rheumatology Research Alliance Consensus Treatment Plans for Juvenile Idiopathic Arthritis-Associated and Idiopathic Chronic Anterior Uveitis. Arthritis Care Res (Hoboken). 2019 Apr;71(4):482-491. doi: 10.1002/acr.23610.

25-Simonini G, Katie D, Cimaz R, Macfarlane GJ, Jones GT. Does switching anti-TNFalpha biologic agents represent an effective option in childhood chronic uveitis: the evidence from a systematic review and metaanalysis approach. Semin Arthritis Rheum. 2014 Aug;44(1):39-46. doi: 10.1016/j.semarthrit.2014.03.001. Epub 2014 Mar 6.

26-Simonini G, Druce K, Cimaz R, Macfarlane GJ, Jones GT. Current evidence of anti-tumor necrosis factor alpha treatment efficacy in childhood chronic uveitis: a systematic review and meta-analysis approach of individual drugs. Arthritis Care Res (Hoboken). 2014 Jul;66(7):1073-84. doi: 10.1002/acr.22214.

27-Ming S, Xie K, He H, Li Y, Lei B. Efficacy and safety of adalimumab in the treatment of non-infectious uveitis: a meta-analysis and systematic review. Drug Des Devel Ther. 2018 Jul 4;12:2005-2016. doi: 10.2147/DDDT.S160431. eCollection 2018.

28-Pato E, Muñoz-Fernández S, Francisco F, Abad MA, Maese J, Ortiz A, Carmona L; Uveitis Working Group from Spanish Society of Rheumatology. Systematic Review on the Effectiveness of Immunosuppressants and Biological 
Therapies in the Treatment of Autoimmune Posterior Uveitis. Semin Arthritis Rheum. 2011 Feb;40(4):314-23. doi: 10.1016/j.semarthrit.2010.05.008. Epub 2010 Jul 24.

29-LaMattina KC, Goldstein DA. Adalimumab for the treatment of uveitis. Expert Rev Clin Immunol. 2017 Mar;13(3):181-188. doi: 10.1080/1744666X.2017.1288097.

30-Zeidan MJ, Saadoun D, Garrido M, Klatzmann D, Six A, Cacoub P. Behçet's disease physiopathology: a contemporary review. Autoimmun Highlights. 2016. https://doi.org/10.1007/s13317-016-0074-1.

31-Ksiaa I, Abroug N, Kechida M, Zina S, Jelliti B, Khochtali S, Attia S, Khairallah M. Eye and Behçet's disease. J Fr Ophtalmol. 2019 Apr;42(4):e133e146. doi: 10.1016/j.jfo.2019.02.002. Epub 2019 Mar 5.

32- International Team for the Revision of the International Criteria for Behçet's Disease (ITR-ICBD). The International Criteria for Behçet's Disease (ICBD): a collaborative study of 27 countrieson the sensitivity and specificity of the new criteria. J Eur Acad Dermatol Venereol 2014;28:338-47.

33-American College of Rheumatology Ad Hoc Committee on GlucocorticoidInduced Osteoporosis. Recommendations for the prevention and treatment of glucocorticoid-induced osteoporosis: 2001 update. Arthritis \& Rheumatism, 44(7), 1496-1503. doi:10.1002/1529-0131(200107)44:7<1496::aidart271>3.0.co;2-5

34-Diretrizes para prevenção e tratamento da osteoporose induzida por glicocorticoide Rev. Bras. Reumatol. vol.52 no. 4 São Paulo July/Aug. 2012. http://dx.doi.org/10.1590/S0482-50042012000400009.

35-Capella MJ, et al. Long-term efficacy and safety of infliximab in the treatment of Behçet's disease. Ocul Immunol Inflamm. 2012. PMID: 22486265 
36-Suhler EB, Lowder CY, Goldstein DA, Giles T, Lauer AK, Kurz PA, Pasadhika S, Lee ST, de Saint Sardos A, Butler NJ, Tessler HH, Smith JR, Rosenbaum JT. Adalimumab therapy for refractory uveitis: results of a multicentre, open-label, prospective trial. Br J Ophthalmol. 2013 Apr;97(4):4816. doi: 10.1136/bjophthalmol-2012-302292. Epub 2013 Feb 2. PMID: 23376607.

37-Handa-Miyauchi M MD, Takase H MD, PhD, Tanaka M MD, Akiyama M PhD, Ohno-Matsui K MD, PhD, Mochizuki M MD,PhD. A Validation Study of the Revised Diagnostic Criteria from the International Workshop on Ocular Sarcoidosis at a Single Institute in Japan.Ocul Immunol Inflamm. 2020 May 29:1-6. doi: 10.1080/09273948.2020.1758159.

38-Erckens RJ, Mostard RL, Wijnen PA, Schouten JS, Drent M. Adalimumab successful in sarcoidosis patients with refractory chronic noninfectious uveitis. Graefes Arch Clin Exp Ophthalmol. 2012 May;250(5):713-20. doi: 10.1007/s00417-011-1844-0. Epub 2011 Nov 27.

39-Jamilloux Y, Kodjikian L, Broussolle C, Sève P. Sarcoidosis and uveitis. Autoimmun Rev. 2014 Aug;13(8):840-9. doi: 10.1016/j.autrev.2014.04.001. Epub 2014 Apr 3.

40-Riancho-Zarrabeitia L, Calvo-Río V, Blanco R, Mesquida M, Adan AM, Herreras JM, Aparicio Á, Peiteado-Lopez D, Cordero-Coma M, García Serrano JL, Ortego-Centeno N, Maíz O, Blanco A, Sánchez-Bursón J, González-Suárez S, Fonollosa A, Santos-Gómez M, González-Vela C, Loricera J, Pina T, González-Gay MA. Anti-TNF-alpha therapy in refractory uveitis associated with sarcoidosis: Multicenter study of 17 patients. Semin Arthritis Rheum. 2015 Dec;45(3):361-8. doi: 10.1016/j.semarthrit.2015.05.010. Epub 2015 May 21.

41-Yang SJ, Salek S, Rosenbaum JT. Ocular sarcoidosis: new diagnostic modalities and treatment. Curr Opin Pulm Med. 2017 Sep;23(5):458-467. doi: 10.1097/MCP.0000000000000409. 
42-Mochizuki M, Smith JR, Takase H, Kaburaki T, Acharya NR, Rao NA; International Workshop on Ocular Sarcoidosis Study Group. Revised criteria of International Workshop on Ocular Sarcoidosis (IWOS) for the diagnosis of ocular sarcoidosis. $\mathrm{Br} J$ Ophthalmol. 2019 Oct;103(10):1418-1422. doi: 10.1136/bjophthalmol-2018-313356. Epub 2019 Feb 23.

43-Pasadhika S, Rosenbaum JT. Ocular Sarcoidosis. Clin Chest Med. 2015 Dec;36(4):669-83. doi: 10.1016/j.ccm.2015.08.009.

44-Gallego-Pinazo R, Dolz-Marco R, Martínez-Castillo S, Arévalo JF, DíazLlopis M. Update on the principles and novel local and systemic therapies for the treatment of non-infectious uveitis. Inflamm Allergy Drug Targets. 2013 Feb;12(1):38-45. doi: 10.2174/1871528111312010006.

45-Thomas AS. Biologics for the treatment of noninfectious uveitis: current concepts and emerging therapeutics. Curr Opin Ophthalmol. 2019 May;30(3):138-150. doi: 10.1097/ICU.0000000000000562.

46-Sánchez-Cano D, et al. Off-label uses of anti-TNF therapy in three frequent disorders: Behçet's disease, sarcoidosis, and noninfectious uveitis.Mediators Inflamm. 2013;2013:286857. doi: 10.1155/2013/286857. Epub 2013 Aug 1.

47-Pasadhika S, Rosenbaum JT. Update on the use of systemic biologic agents in the treatment of noninfectious uveitis. Biologics. 2014 Feb 15;8:67-81. doi: 10.2147/BTT.S41477. eCollection 2014.

48-Okhravi N, Odufuwa B, McCluskey P, Lightman S. Scleritis. Surv Ophthalmol. 2005 Jul-Aug;50(4):351-63. doi: 10.1016/j.survophthal.2005.04.001.

49-Sen HN, Sangave AA, Goldstein DA, Suhler EB, Cunningham D, Vitale S, Nussenblatt RB. A standardized grading system for scleritis. Ophthalmology. 2011 Apr;118(4):768-71. doi: 10.1016/j.ophtha.2010.08.027. Epub 2010 Nov 20. 
50-Sainz de la Maza M, Molina N, Gonzalez-Gonzalez LA, Doctor PP, Tauber

J, Foster CS. Scleritis therapy. Ophthalmology. 2012 Jan;119(1):51-8. doi: 10.1016/j.ophtha.2011.07.043. Epub 2011 Oct 19.

51-Oray $M$, et al. Diagnosis and management of non-infectious immunemediated scleritis: current status and future prospects. Expert Rev Clin Immunol. 2016. PMID: 27055583 Review.

52-Nevares A, Raut R, Libman B, Hajj-Ali R. Noninfectious Autoimmune Scleritis: Recognition, Systemic Associations, and Therapy. Curr Rheumatol Rep. 2020 Mar 26;22(4):11. doi: 10.1007/s11926-020-0885-y.

53-Stem MS, Todorich B, Faia LJ. Ocular Pharmacology for Scleritis: Review of Treatment and a Practical Perspective. J Ocul Pharmacol Ther. 2017 May;33(4):240-246. doi: 10.1089/jop.2016.0127. Epub 2017 Mar 29.

54-Beardsley RM, Suhler EB, Rosenbaum JT, Lin P. Pharmacotherapy of scleritis: current paradigms and future directions. Expert Opin Pharmacother. 2013 Mar;14(4):411-24. doi: 10.1517/14656566.2013.772982. Epub 2013 Feb.

55-Sohn EH, Wang R, Read R, et al. Long-term, multicenter evaluation of subconjunctival injection of triamcinolone for non-necrotizing, noninfectious anterior scleritis. Ophthalmology. 2011;118(10):1932-1937.

56-Jabs DA, Akpek EK. Immunosuppression for posterior uveitis. Retina. 2005 Jan;25(1):1-18. doi: 10.1097/00006982-200501000-00001.

57-Jabs DA, Rosenbaum JT, Foster CS, Holland GN, Jaffe GJ, Louie JS, Nussenblatt RB, Stiehm ER, Tessler H, Van Gelder RN, Whitcup SM, Yocum D. Guidelines for the use of immunosuppressive drugs in patients with ocular inflammatory disorders: recommendations of an expert panel. Am J Ophthalmol. 2000 Oct;130(4):492-513. doi: 10.1016/s0002-9394(00)00659-0. 
58-Ragam A, et al. Treatment of chronic, noninfectious, nonnecrotizing scleritis with tumor necrosis factor alpha inhibitors. Ocul Immunol Inflamm. 2014 Dec;22(6):469-77. doi: 10.3109/09273948.2013.863944. Epub 2013 Dec 19.

59-Doctor P, Sultan A, Syed S, Christen W, Bhat P, Foster CS. Infliximab for the treatment of refractory scleritis. Br J Ophthalmol. 2010 May;94(5):579-83. doi: 10.1136/bjo.2008.150961. Epub 2009 Dec 2.

60-Ozdal PC, Berker N, Tugal-Tutkun I. Pars Planitis: Epidemiology, Clinical Characteristics, Management and Visual Prognosis. J Ophthalmic Vis Res. 2015 Oct-Dec;10(4):469-80. doi: 10.4103/2008-322X.176897.

61-Majumder PD, Biswas J. Pediatric uveitis: An update. Oman J Ophthalmol. 2013 Sep;6(3):140-50. doi: 10.4103/0974-620X.122267.

62-Serna-Ojeda JC, Pedroza-Seres M. Treatment with immunosuppressive therapy in pacientes with pars planitis: experience of a reference centre in Mexico. Br J Ophthalmol. 2014 Nov;98(11):1503-7. doi: 10.1136/bjophthalmol2014-304913. Epub 2014 Jul 1.

63-Ashkenazy N, Saboo US, Abraham A, Ronconi C, Cao JH. Successful treatment with infliximab after Adalimumab failure in pediatric noninfectious uveitis. J AAPOS. 2019 Jun;23(3):151.e1-151.e5. doi: 10.1016/j.jaapos.2019.02.006. Epub 2019 May 4.

64-Khan MA, Haroon M, Rosenbaum JT. Acute Anterior Uveitis and Spondyloarthritis: More Than Meets the Eye. Curr Rheumatol Rep. 2015 Sep;17(9):59. doi: 10.1007/s11926-015-0536-x.

65-Biggioggero M, Crotti C, Becciolini A, Miserocchi E, Favalli EG. The Management of Acute Anterior Uveitis Complicating Spondyloarthritis: Present and Future.Biomed Res Int. 2018 Oct 14;2018:9460187. doi: 10.1155/2018/9460187. eCollection 2018. 
66-Jhaj G, Kopplin LJ. Ocular features of the HLA-B27-positive seronegative spondyloarthropathies. Curr Opin Ophthalmol. 2018 Nov;29(6):552-557. doi: 10.1097/ICU.0000000000000525.

67-Rademacher J, Poddubnyy D, Pleyer U. Uveitis in spondyloarthritis. Ther Adv Musculoskelet Dis. 2020 Sep 12;12:1759720X20951733. doi: 10.1177/1759720X20951733

68-Sharma SM, Jackson D, Uveitis and spondyloarthropathies, Best Practice \& Research Clinical Rheumatology (2018), https://doi.org/10.1016/j.berh.2018.08.002.

69-Wakefield D, Clarke D, McCluskey P. Recent Developments in HLA B27 Anterior Uveitis. Front Immunol. 2021 Jan 5;11:608134. doi: 10.3389/fimmu.2020.608134. eCollection 2020.

70-Zu Hoerste MM, Walscheid K, Tappeiner C, Zurek-Imhoff B, Heinz C, Heiligenhaus $A$. The effect of methotrexate and sulfasalazine on the course of HLA-B27-positive anterior uveitis: results from a retrospective cohort study. Graefes Arch Clin Exp Ophthalmol. 2018 Oct;256(10):1985-1992. doi: 10.1007/s00417-018-4082-x. Epub 2018 Aug 1.

71-Kim M, Won JY, Choi SY, Ju JH, Park YH. Anti-TNFalpha Treatment for HLA-B27-Positive Ankylosing Spondylitis-Related Uveitis. Am J Ophthalmol. 2016 Oct;170:32-40. doi: 10.1016/j.ajo.2016.07.016. Epub 2016 Jul 25.

72-Wu D, Guo YY, Xu NN, Zhao S, Hou LX, Jiao T, Zhang N. Efficacy of antitumor necrosis factor therapy for extra-articular manifestations in patients with ankylosing spondylitis: a meta-analysis. BMC Musculoskelet Disord. 2015 Feb 10;16(1):19. doi: 10.1186/s12891-015-0489-2.

73-Van der Horst-Bruinsma I, van Bentum R, Verbraak FD, et alThe impact of certolizumab pegol treatment on the incidence of anterior uveitis flares in 
patients with axial spondyloarthritis: 48-week interim results from C-VIEWRMD Open 2020;6:e001161. doi: 10.1136/rmdopen-2019-001161.

74-Van Bentum RE, Heslinga SC, Nurmohamed MT, Gerards AH, Griep EN, Koehorst CBJM, Kok MR, Schilder AM, Verhoef M, van der Horst-Bruinsma IE. Reduced Occurrence Rate of Acute Anterior Uveitis in Ankylosing Spondylitis Treated with Golimumab - The GO-EASY Study. J Rheumatol. 2019 Feb;46(2):153-159. doi: 10.3899/jrheum.180312. Epub 2018 Nov 1.

75-Prete M, Guerriero S, Dammacco R, Fatone MC, Vacca A, Dammacco F, Racanelli V. Autoimmune uveitis: a retrospective analysis of 104 patients from a tertiary reference center. J Ophthalmic Inflamm Infect. 2014 Jul 24;4:17. doi: 10.1186/s12348-014-0017-9. eCollection 2014.

76-Gómez-Gómez A, et al. Efficacy and safety of immunomodulatory drugs in patients with anterior uveitis: A systematic literature review. Medicine (Baltimore). 2017 Oct;96(42):e8045. doi: 10.1097/MD.0000000000008045.

77-Heiligenhaus A, et al. Similarities in clinical course and outcome between juvenile idiopathic arthritis (JIA)-associated and ANA-positive idiopathic anterior uveitis: data from a population-based nationwide study in Germany. Arthritis Res Ther. 2020 Apr 15;22(1):81. doi: 10.1186/s13075-020-02166-3.

78-Bachta A, Kisiel B, Tłustochowicz M, Raczkiewicz A, Rękas M, Tłustochowicz W. High Efficacy of Methotrexate in Patients with Recurrent Idiopathic Acute Anterior Uveitis: a Prospective Study. Arch Immunol Ther Exp (Warsz). 2017 Feb;65(1):93-97. doi: 10.1007/s00005-016-0402-1. Epub 2016 May 11.

79-Vallet $\mathrm{H}$, et al. Infliximab Versus Adalimumab in the Treatment of Refractory Inflammatory Uveitis: A Multicenter Study From the French Uveitis Network.Arthritis Rheumatol. 2016 Jun;68(6):1522-30. doi: 10.1002/art.39667. 
80-Du L, Kijlstra A, Yang P. Vogt-Koyanagi-Harada disease: Novel insights into pathophysiology, diagnosis and treatment. Prog Retin Eye Res. 2016 May; 52:84-111.

81-Cunningham ET Jr, Rathinam SR, Tugal-Tutkun I, Muccioli C, Zierhut M. Vogt-Koyanagi-Harada Disease. Ocul Immunol Inflamm. 2014 Aug;22(4):24952.

82-Burkholder BM. Vogt-Koyanagi-Harada disease. Curr Opin Ophthalmol. 2015 Nov;26(6):506-11.

83- Read RW, Holland GN, Rao NA, Tabbara KF, Ohno S, Arellanes-Garcia L, Pivetti-Pezzi P, Tessler HH, Usui M. Revised diagnostic criteria for VogtKoyanagi-Harada disease: report of an international committee on nomenclature. Am J Ophthalmol. 2001 May; 131(5): 647-52.

84-Silpa-Archa S, Silpa-Archa N, Preble JM, Foster CS. Vogt-Koyanagi-Harada Syndrome: Perspectives for Immunogenetics, Multimodal Imaging and Therapeutic Option. Autoimmun Rev. 2016 Aug;15(8):809-19.

85-Arevalo JF, Garcia RA, Al-Dhibi HA, Sanchez JG, Suarez-Tata L. Update on sympathetic ophthalmia. Middle East Afr J Ophthalmol. 2012 Jan;19(1):13-21. doi: 10.4103/0974-9233.92111.

86-Greco A, Fusconi M, Gallo A, Turchetta R, Marinelli C, Macri GF, De Virgilio A, de Vincentiis M. Vogt-Koyanagi-Harada syndrome. Autoimmun Rev. 2013 Sep;12(11):1033-8. doi: 10.1016/j.autrev.2013.01.004. Epub 2013 Apr 6.

87-O'Keefe GA, Rao NA. Vogt-Koyanagi-Harada disease. Surv Ophthalmol. 2017 Jan-Feb;62(1):1-25. doi: 10.1016/j.survophthal.2016.05.002. Epub 2016 May 27.

88- Couto C, Schlaen A, Frick M, Khoury M, Lopez M, Hurtado E, Goldstein D. Adalimumab Treatment in Patients with Vogt-Koyanagi-Harada Disease. Ocul 
Immunol Inflamm. 2018;26(3):485-489. doi: 10.1080/09273948.2016.1236969. Epub 2016 Oct 24.

89-Foster CS, Kothari S, Anesi SD, Vitale AT, Chu D, Metzinger JL, Cerón O. The Ocular Immunology and Uveitis Foundation preferred practice patterns of uveitis management. Surv Ophthalmol. 2016 Jan-Feb;61(1):1-17. doi: 10.1016/j.survophthal.2015.07.001. Epub 2015 Jul 9.

90-Choi J, Hawley DP, Ashworth J, Edelsten C, Bossuyt ASAM. An update on the modern management of paediatric uveitis. Br J Ophthalmol. 2019 Jul 4. pii: bjophthalmol-2019-314212. doi: 10.1136/bjophthalmol-2019-314212. [Epub ahead of print]

91- Hullah EA, Blaker PA, Marinaki AM, Escudier MP, Sanderson JD. A practical guide to the use of thiopurines in oral medicine. J Oral Pathol Med. 2015 Nov;44(10):761-8.

92-Airody A, Heath G, Lightman S, Gale R. Non-Infectious Uveitis: Optimising the Therapeutic Response. Drugs. 2016 Jan;76(1):27-39.

93-Hoy SM. Adalimumab: A Review in Non-Infectious Non-Anterior Uveitis. BioDrugs. 2017 Apr;31(2):135-142.

94-Brasil. Ministério da Saúde. Hepatites Virais. Brasília: MS; 2007. Disponível em: <https://bvsms.saude.gov.br/bvs/publicacoes/07_0044_M2.pdf>. Acesso em: 20 jan. 2021. 